\title{
Diurnal and seasonal dynamics of solar-induced chlorophyll fluorescence, vegetation indices, and gross primary productivity in the boreal forest
}

\author{
Zoe Pierrat $^{1}$, Troy Magney ${ }^{2}$, Nicholas C. Parazoo ${ }^{3,7}$, Katja Grossmann ${ }^{4}$, \\ David R. Bowling ${ }^{5}$, Ulli Seibt ${ }^{1}$, Bruce Johnson ${ }^{6}$, Warren Helgason ${ }^{6}$, Alan \\ Barr $^{6}$, Jacob Bortnik ${ }^{1}$, Alexander Norton ${ }^{3}$, Andrew Maguire ${ }^{3}$, Christian \\ Frankenberg $^{7}$, Jochen Stutz ${ }^{1}$ \\ ${ }^{1}$ University of California Los Angeles \\ ${ }^{2}$ University of California Davis \\ ${ }^{3}$ Jet Propulsion Laboratory, California Institute of Technology \\ ${ }^{4}$ University of Heidelberg \\ ${ }^{5}$ University of Utah \\ ${ }^{6}$ University of Saskatchewan \\ ${ }^{7}$ California Institute of Technology
}

Key Points:

- Tower-based SIF closely tracks GPP over two years in a mixed-species boreal forest.

- Light saturation of photosynthesis drives non-linearity between SIF and GPP.

- The SIF-GPP relationship is seasonally variant due to dynamics between LUEF and $\mathrm{LUE}_{\mathrm{P}}$.

Corresponding author: Zoe Pierrat, zpierrat@g.ucla.edu

Corresponding author: Jochen Stutz, jochen@atmos.ucla.edu

This article has been accepted for publication and ${ }^{-1}$ undergone full peer review but has not been through the copyediting, typesetting, pagination and proofreading process, which may lead to differences between this version and the Version of Record. Please cite this article as doi: 10.1029/2021JG006588.

This article is protected by copyright. All rights reserved. 


\section{Abstract}

Remote sensing of solar-induced chlorophyll fluorescence (SIF) provides a powerful proxy for gross primary productivity (GPP). It is particularly promising in boreal ecosystems where seasonal downregulation of photosynthesis occurs without significant changes in canopy structure or chlorophyll content. The use of SIF as a proxy for GPP is complicated by inherent non-linearities due to both physical (illumination effects) and ecophysiological (light use efficiencies) controls at fine spatial (tower/leaf) and temporal (halfhourly) scales. To study the SIF-GPP relationship, we investigated the diurnal and seasonal dynamics of continuous tower-based measurements of SIF, GPP, and common vegetation indices at the Southern Old Black Spruce Site (SOBS) in Saskatchewan, CA over the course of two years. We find that SIF outperforms other vegetation indices as a proxy for GPP at all temporal scales but shows a non-linear relationship with GPP at a halfhourly resolution. At small temporal scales, SIF and GPP are predominantly driven by light and non-linearity between SIF and GPP is due to the light saturation of GPP. Averaged over daily and monthly scales, the relationship between SIF and GPP is linear due to a reduction in the observed PAR range. Seasonal changes in the light responses of SIF and GPP are driven by changes in light use-efficiency which co-vary with changes in temperature, while illumination and canopy structure partially linearize the SIF-GPP relationship. Additionally, we find that the SIF-GPP relationship has a seasonal dependency. Our results help to clarify the utility of SIF for estimating carbon assimilation in boreal forests.

\section{Plain Language Summary}

Remote sensing can help us better understand plants role in the global carbon cycle. In particular, a small light signal emitted by plants during photosynthesis, known as solar-induced chlorophyll fluorescence (SIF), is a promising remotely sensed proxy for carbon uptake due to its strong relationship with Gross Primary Productivity (GPP, ecosystem carbon assimilated during photosynthesis) when observed by satellite. Recent work at the leaf and tower-scale has highlighted differences in the relationship between SIF and GPP, thereby raising questions over the utility of SIF for this purpose. We collect tower-based SIF and GPP measurements from the southern end of the boreal forest to clarify their connection in boreal ecosystems. We find that temporal resolution is critical for understanding the nuances between SIF and GPP and that light and temper- 
ature effects complicate their relationship. Additionally, the relationship between SIF and GPP has a seasonal dependency that should be considered when using SIF. Taken together, our results suggest that SIF is a powerful tool for estimating carbon assimilation in boreal forests, but that some key considerations need to be addressed for properly interpreting this faint signal.

\section{Introduction}

Uncertainties in future climate projections are, in large part, due to an incomplete understanding of terrestrial carbon and ecosystem feedbacks (Friedlingstein et al., 2014). Among the most poorly understood ecosystems is the boreal forest, which stores a significant amount of carbon and is one of the regions most sensitive to environmental change (Thurner et al., 2014; Bonan, 2008; Schaefer et al., 2014; Fisher et al., 2018; Goetz et al., 2005; Fu et al., 2017). Therefore, a more complete understanding of environmental controls on boreal forest productivity is critical for predicting future carbon cycle feedbacks in this ecosystem (Anav et al., 2015; Parazoo et al., 2018).

Remotely sensed metrics are a powerful tool for understanding and scaling plant responses to the environment across space and time (Frankenberg \& Berry, 2017; Gamon et al., 1997, 2016; Jeong et al., 2017; Tucker, 1979). Vegetation indices (VIs) that measure greeness, such as the Normalized Difference Vegetation Index (NDVI) or the Near-Infrared Reflectance from vegetation (NIRv) have proven to be effective at tracking plant productivity in ecosystems where chlorophyll content and carbon uptake are closely correlated, such as deciduous forests and grasslands (Tucker, 1979; Badgley et al., 2017; H. Yang et al., 2017; Wang et al., 2019). These measures often fail to predict productivity in evergreen systems, such as the boreal forest, where changes to photosynthesis often occur without significant changes in canopy structure or chlorophyll content (Springer et al., 2017; Sims, Rahman, et al., 2006; Magney, Bowling, et al., 2019; Walther et al., 2016; Jeong et al., 2017; Pierrat et al., 2021). In contrast to greeness based VIs, solar-induced chlorophyll fluorescence (SIF) is a particularly promising remote sensing metric for tracking changes in gross primary productivity (GPP). SIF has been reported to exhibit a linear relationship with GPP at the ecosystem scale across diverse biomes when measured from satellites (Commane et al., 2017; Jeong et al., 2017; Luus et al., 2017; Walther et al., 2016). 
SIF has a mechanistic connection to photosynthetic activity (Magney, Bowling, et al., 2019; Magney et al., 2020; Porcar-Castell et al., 2014, 2021). In all plants, a photon of light absorbed by chlorophyll follows one of three potential pathways: it can be used to drive photochemistry (photochemical quenching (PQ)), it can be dissipated as heat (non-photochemical quenching (NPQ)), or it can be re-emitted as fluorescence (SIF) (Krause \& Weis, 1991). The dynamic relationships inherent in these three pathways determine the utility of SIF as a proxy for GPP (Magney et al., 2020). Studies at the leaf level have shown that the yield of fluorescence and yield of photochemistry are proportional under moderate light conditions (Porcar-Castell et al., 2014; Van Der Tol et al., 2014). However, there is a limited understanding of the dynamics of these processes at the canopy scale and under natural conditions such as seasonally varying NPQ and PQ in boreal ecosystems. Recent work has highlighted nuanced relationships between fluorescence and photochemistry, thereby motivating further studies investigating the utility of SIF as a proxy for GPP (Kim et al., 2021; Maguire et al., 2020; Marrs et al., 2020; Dechant et al., 2020).

Fluorescence measured at the canopy scale under natural conditions (SIF) can be described with the following equation:

$$
\mathrm{SIF}=\mathrm{APAR} \times \mathrm{LUE}_{\mathrm{F}} \times f_{\text {esc }}
$$

where APAR is the photosynthetically active radiation absorbed by chlorophyll defined as:

$$
\mathrm{APAR}=\mathrm{PAR} \times f \mathrm{PAR}
$$

PAR is photosynthetically active radiation and $f$ PAR is the fraction of PAR absorbed by chlorophyll. LUE $\mathrm{F}$ is the light use efficiency of fluorescence and $f_{\text {esc }}$ is the probability that an emitted photon will escape the canopy. The impact of $f_{e s c}$ and canopy structural effects can be considered by calculating the theoretical emitted SIF at the leaf level, $\mathrm{SIF}_{\text {total }}$, as:

$$
\mathrm{SIF}_{\text {total }}=\frac{\mathrm{SIF}}{f_{\text {esc }}}
$$


where SIF is the observed SIF signal from an instrument with a particular viewing geometry. $f_{e s c}$ can be estimated in the far-red following Zeng et al. (2019):

$$
f_{\text {esc }}=\frac{\mathrm{NIRv}}{f \mathrm{PAR}}
$$

Theoretically, NIRv represents the fraction of near-infrared light that originates from vegetation and minimizes the influence of soil or background reflectances (Badgley et al., 2017). Thus, it is a good measure of canopy structure and chlorophyll content (Badgley et al., 2017) and can be used for estimating $f_{e s c}$ of SIF in the near-infrared (Zeng et al., 2019). In cropping systems, the structural influences on SIF (APAR and $f_{\text {esc }}$ ) have been shown to be the dominant drivers of SIF variability (Dechant et al., 2020). In evergreen needleleaf forests, $f_{\text {esc }}$ changes little over the seasonal cycle due to the fact that such forests remain structurally invariant across seasons (Magney, Bowling, et al., 2019; Stylinski et al., 2002; Badgley et al., 2019; Sims, Luo, et al., 2006; Garbulsky et al., 2010). Little empirical evidence for this assumption has been presented and significant questions remain over how $f_{\text {esc }}$ impacts SIF over shorter temporal scales and under a variety of illumination conditions. Thus, additional analysis on how canopy structure and illumination conditions impact SIF is necessary.

Canopy integrated carbon uptake via photosynthesis, also known as Gross Primary Productivity (GPP), can be expressed as:

$$
\mathrm{GPP}=\mathrm{APAR} \times \mathrm{LUE}_{\mathrm{P}}
$$

where $\mathrm{LUE}_{\mathrm{P}}$ is the light use efficiency of photosynthesis (Monteith, 1972). LUE is a complex function of leaf biochemistry and APAR, and is often expressed as a hyperbolic function of APAR (Michaelis \& Menten, 1913):

$$
\mathrm{LUE}_{\mathrm{P}}=\frac{\mathrm{GPP}_{\max }}{c+\mathrm{APAR}}
$$

where $c$ is a coefficient in radiance units and $\mathrm{GPP}_{\max }$ is the photosynthetic capacity of the system (i.e. GPP of the canopy at light saturation). In practice, $c$ represents the APAR value at which GPP reaches half of GPP $\max$ in a GPP light response curve. Therefore, it depends on the electron transport rate as well as a plant's rate of carboxy- 
lation, which both vary based on plant responses to environmental conditions including temperature and available water. We can combine Equations 1 and 5 by eliminating APAR to arrive at (Guanter et al., 2014; Frankenberg \& Berry, 2017):

$$
\mathrm{GPP}=\mathrm{SIF} \times \frac{\mathrm{LUE}_{\mathrm{P}}}{\mathrm{LUE}_{\mathrm{F}} \times f_{\text {esc }}}
$$

Studies at the satellite scale over a variety of ecosystems have shown that SIF and GPP are linearly proportional (Frankenberg \& Berry, 2017; Sun et al., 2017, 2018). However, the reason for the linear relationship is unclear, as $\mathrm{LUE}_{\mathrm{P}}$ has a non-linear relationship with light (Equation 6). Further combining Equations 6 and 7, we find a more complete functional relationship between SIF and GPP (Damm et al., 2015):

$$
\mathrm{GPP}=\frac{\mathrm{SIF} \times \mathrm{GPP}_{\max }}{a+\mathrm{SIF}}
$$

where $a=c \times f_{e s c} \times \mathrm{LUE}_{\mathrm{F}}$. Damm et al. (2015) notes that because this equation is an approximation of the complex relationships between SIF and GPP, Equation 8 performs best when $a$ is assumed constant or SIF corresponds to APAR. This assumption is reasonable under conditions where variations in $\mathrm{LUE}_{\mathrm{F}}$ are substantially smaller than variations in $\mathrm{LUE}_{\mathrm{P}}$, such as cropping systems (Van Der Tol et al., 2014). However, this assumption breaks down in high latitude evergreen systems, such as the boreal forest, which experience strong seasonal changes in $\mathrm{LUE}_{\mathrm{P}}$ associated with photochemical downregulation of photosynthesis over winter (Middleton et al., 1997). Further, it is currently unclear how strong changes in environmental conditions over the course of the season impact $\mathrm{LUE}_{\mathrm{F}}$ and $\mathrm{LUE}_{\mathrm{P}}$. Therefore, there is a critical need for experimental data to better quantify the SIF-GPP relationship in systems with highly dynamic LUE P $_{\mathrm{P}}$ and environmental extremes in light and temperature.

Boreal evergreen needleleaf species experience strong seasonal changes in photosynthesis as a consequence of the physiological stresses of winter as well as dynamic changes in PAR. In order to avoid damage from excess light, both seasonally and diurnally, evergreen needleleaf plants utilize two forms of NPQ, which regulate the dynamics of photochemistry and fluorescence (Verhoeven, 2014; Demmig-Adams \& Adams, 1992). The first form is rapidly reversible and therefore important during times of active photochemistry and high photosynthetically active radiation (PAR). The photochemical reflectance index (PRI) is a useful indicator of this form (Gamon et al., 1992; Gamon \& Berry, 2012; 
Wong \& Gamon, 2015b, 2015a). Sustained NPQ is associated with seasonal downregulation of photosynthesis (Adams et al., 2004; Öquist \& Huner, 2003; Verhoeven, 2014; Jahns \& Holzwarth, 2012; Adams \& DemmigAdams, 1994). In evergreen systems, the remotely sensed chlorophyll-carotenoid index (CCI) is a remote sensing proxy for sustained NPQ (Gamon et al., 2016). Both rapidly reversible and sustained NPQ influence the seasonal and diurnal dynamics between SIF and GPP in Boreal evergreen forests.

Our current understanding indicates that both the physical $\left(f_{\text {esc }}\right)$ and the ecophysiological $\left(\mathrm{LUE}_{\mathrm{F}}, \mathrm{LUE}_{\mathrm{P}}\right)$ drivers of the SIF-GPP relationship operate on varying temporal scales and can be measured using a combination of remotely sensed indices. Therefore, a better understanding of these drivers, both at a high temporal resolution and seasonally, is necessary to assess the utility of SIF as a proxy for GPP in boreal ecosystems. In our study, we seek to answer:

1. How do the relationships between SIF, VIs, and GPP change across varying temporal scales?

2. How do the dynamics of $\mathrm{LUE}_{\mathrm{P}}, \mathrm{LUE}_{\mathrm{F}}$, and $f_{\text {esc }}$ impact the relationship between SIF and GPP?

Tower-based spectrometer systems allow for a deeper investigation of the physical and ecophysiological drivers of the SIF-GPP relationship and aid our ability to scale measurements from the leaf to orbit by filling the spatio-temporal gap between leaf level and satellite level measurements (Grossmann et al., 2018). Here, we present data from a towerbased spectrometer system (Sections 2.1-2.4) and a statistical analysis (Section 2.5) to determine the linkages between SIF and GPP at varying temporal resolutions (Section 3.1), to statistically connect changes in SIF and GPP to environmental controls (Section 3.2), and to provide a seasonally resolved SIF-GPP parametrization (Section 3.3) for the implementation of this ecosystem in carbon cycle models. These results then elucidate the answers to our scientific questions (Section 4).

\section{Materials and Methods}

Tower-based SIF spectrometer systems have already provided valuable insights into the SIF-GPP relationship in cropping (Magney, Frankenberg, et al., 2019; He et al., 2020), temperate (Kim et al., 2021; H. Yang et al., 2017; X. Yang et al., 2015), and sub-alpine evergreen systems (Magney, Bowling, et al., 2019; Cheng et al., 2020). However, few mea- 
surements in boreal ecosystems have been reported (Pierrat et al., 2021). We collected tower-based SIF and vegetation index (VI) data along with GPP and meteorological data from a boreal field site in Canada to answer our scientific questions. Details of the site, observational methods, and analysis approach are discussed in the following sections.

\subsection{Site Description: Southern Old Black Spruce}

The study site (Southern Old Black Spruce, SOBS, Fluxnet ID CA-Obs) is located near the southern limit of the boreal forest ecotone in Saskatchewan, Canada $\left(53.98^{\circ} \mathrm{N}\right.$, $105.12^{\circ} \mathrm{W}$ ) (Figure 1) (Jarvis et al., 1997). It is a mixed forest stand with stem density predominantly (90\%) black spruce (Picea mariana), and scattered (10\%) larch (Larix laricina) (Pappas et al., 2020). Average canopy height at the site is $\sim 16 \mathrm{~m}$ with a canopy leaf area index of $\sim 3.8 \mathrm{~m}^{2} \mathrm{~m}^{-2}$ (Chen et al., 2006). Long-term (1981-2010) mean annual air temperature and total precipitation in the area are $1.4^{\circ} \mathrm{C}$ and $427.7 \mathrm{~mm}$ respectively. There is an average of 146 days with a snow depth of $1 \mathrm{~cm}$ or more (Government of Canada, Prince Albert Station, 2019). The site is equipped with a $26 \mathrm{~m}$ above ground level (agl) twin scaffold tower, approximately twice the height of the forest canopy. Phenological transitions typically occur April-May and September-October (Pierrat et al., 2021; Grant et al., 2009; Bergeron et al., 2007).

\subsection{Remote Sensing: PhotoSpec}

We collected remotely sensed measurements (NDVI, NIRv, PRI, CCI, far-red SIF) using PhotoSpec (see Grossmann et al. (2018) for detailed instrument description) from September 2018 to the end of December 2020. Photospec was installed at the top of the scaffolding tower $(26 \mathrm{~m} \mathrm{agl})$ facing due north. It has a narrow field of view $\left(0.7^{\circ}\right), 2$-D scanning capabilities, and can simultaneously measure SIF along with vegetation indices at the same point in the canopy (Grossmann et al., 2018). Our scanning strategy had three 'elevation scans' (scanning vertically with $0^{\circ}$ horizontally at the horizon) at $35^{\circ} \mathrm{W}$ $\left(10\right.$ measurements, elevations $-50^{\circ}$ to $-23^{\circ}$ in steps of $\left.3^{\circ}\right), 0^{\circ} \mathrm{N}(24$ measurements, elevations $-80^{\circ}$ to $-11^{\circ}$ in steps of $3^{\circ}$ ), and $35^{\circ} \mathrm{E}$ (10 measurements, elevations $-70^{\circ}$ to $-25^{\circ}$ in steps of $5^{\circ}$ ) and three individual targets on a larch (Figure 1). This scan strategy and subsequent averaging is representative of the forest because it reflects the stem density of the forest with $\sim 90 \%$ of targets hitting black spruce and $\sim 10 \%$ of targets hitting larch. 


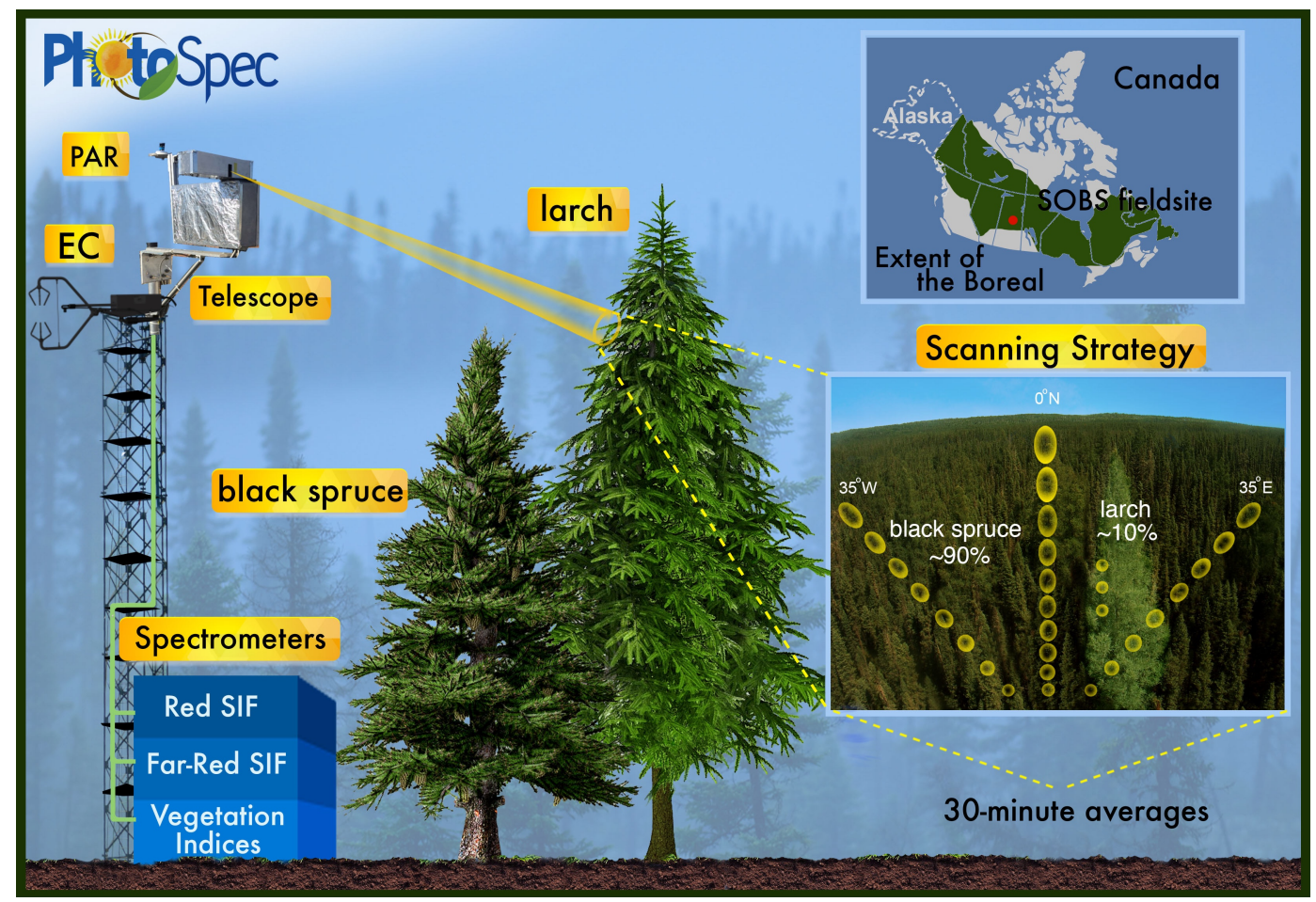

Figure 1. Field site location with PhotoSpec and eddy-covariance (EC) measurements at the Southern Old Black Spruce (SOBS) site in Saskatchewan, Canada. PhotoSpec set up is shown with an inset of the scanning strategy and measurement points on both black spruce and larch. Adapted from (Pierrat et al., 2021). 
Individual measurements take approximately 20 seconds and the complete scan cycle repeats on a 30 minute loop to compare with GPP and environmental variables.

Vegetation indices were calculated as follows, with $\rho_{n m: n m}=$ the average reflectance across a wavelength range in $\mathrm{nm}$ :

$$
\begin{aligned}
& \text { NDVI }=\left(\rho_{830: 860}-\rho_{620: 670}\right) /\left(\rho_{830: 860}+\rho_{620: 670}\right) \quad(\text { Tucker, } 1979) \\
& \mathrm{NIRv}=\left(\rho_{830: 860}-\rho_{620: 670}\right) /\left(\rho_{830: 860}+\rho_{620: 670}\right) \times \rho_{830: 860} \quad(\text { Badgley etal.,2017 }) \\
& \mathrm{PRI}=\left(\rho_{569: 571}-\rho_{520: 532}\right) /\left(\rho_{569: 571}+\rho_{520: 532}\right) \quad(\text { Gamon etal.,1992) } \\
& \mathrm{CCI}=\left(\rho_{520: 532}-\rho_{620: 670}\right) /\left(\rho_{520: 532}+\rho_{620: 670}\right) \quad(\text { Gamon etal.,2016) }
\end{aligned}
$$

SIF was retrieved in the far-red $(745-758 \mathrm{~nm})$ wavelength range using a Fraunhoferline based fitting algorithm (Grossmann et al., 2018). The Fraunhofer-line based approach makes SIF retrievals insensitive to atmospheric scattering and therefore robust even under cloudy sky conditions (Frankenberg et al., 2011; Mohammed et al., 2019; Chang et al., 2020). We collected 1 second PAR data from a LI-COR LI-190R sensor and used these data to remove PhotoSpec measurements where PAR conditions changed significantly $\left(\mathrm{PAR}_{\mathrm{std}}>0.2 \times \mathrm{PAR}_{\mathrm{avg}}\right)$ over the PhotoSpec integration time. We excluded low-quality retrievals where the SIF retrieval error (Grossmann et al., 2018) was $>0.2 \mathrm{Wm}^{-2} \mathrm{sr}^{-1} \mu \mathrm{m}^{-1}$ and where SIF $<-0.1 \mathrm{Wm}^{-2} \mathrm{sr}^{-1} \mu \mathrm{m}^{-1}$ or SIF $>10 \mathrm{Wm}^{-2} \mathrm{sr}^{-1} \mu \mathrm{m}^{-1}$. Finally, we only considered observations where the Solar Zenith Angle $(\mathrm{SZA})<80^{\circ}$ to remove data where low light conditions increase retrieval uncertainty.

We used $f_{\text {esc }}$ to calculate $\mathrm{SIF}_{\text {total }}$ (Equation 3) and to evaluate canopy structure and illumination influences on SIF for each observation. We calculated $f_{\text {esc }}$ following Equation 4 using NIRv and $f$ PAR, which was estimated as:

$$
f \mathrm{PAR}=1-\frac{\text { PAR }_{\text {canopy }}}{\text { PAR }}
$$

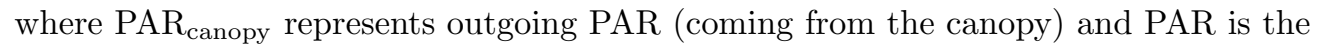
incoming PAR (pointing directly up). PAR canopy was calculated by integrating the calibrated radiance between 400 and $700 \mathrm{~nm}$ measured from PhotoSpec and multiplying by $\pi$ to convert to hemispheric $\mathrm{PAR}_{\text {canopy }}$. PAR was calculated by averaging the 1 second LI-COR LI-190R PAR measurements over the PhotoSpec integration time. We de- 
termined APAR following Equation 2. We calculated $\mathrm{LUE}_{\mathrm{F}}$ following Equation $1\left(\mathrm{LUE}_{\mathrm{F}}=\right.$ $\left.\frac{\mathrm{SIF}}{\operatorname{APAR} * f_{e s c}}\right)$ and $\mathrm{LUE}_{\mathrm{P}}$ following Equation $5\left(\mathrm{LUE}_{\mathrm{P}}=\frac{\mathrm{GPP}}{\mathrm{APAR}}\right)$.

We calculated averages over each 30-minute period across the full spatial scan to reflect stem density of the canopy and match GPP observations. 30-minute spatial averages were again averaged to report daily and monthly averages. Standard deviation of the diurnal variability was significantly greater than measurement errors (Grossmann et al., 2018) and is thus reported along with daily averages throughout the study.

Days with snow cover were identified visually using phenocam images from the site (https://phenocam.sr.unh.edu/webcam/sites/canadaOBS/). Snow cover identification was used to provide context to observed signals but data were not removed from the analysis.

\subsection{Gross Primary Production}

Eddy-covariance (EC) measurements of net ecosystem exchange (NEE) ( $\mu$ mol C $\left.\mathrm{m}^{-2} \mathrm{~s}^{-1}\right)$ and friction velocity $\mathrm{u}^{*}\left(\mathrm{~ms}^{-1}\right)$ were made from atop the site's $26 \mathrm{~m}$ scaffold tower from July 2019 through the end of December 2020. The EC system consisted of a 3-D sonic anemometer (CSAT3, Campbell Scientific, Logan, UT) in combination with a closedpath infrared gas $\left(\mathrm{CO}_{2} / \mathrm{H}_{2} \mathrm{O}\right)$ analyzer (LI-7200 analyzer, Li-Cor, Lincoln, NE)) operated in absolute mode. The 30-min eddy fluxes were computed using the Eddy-Pro software (version 7.0.6, Li-Cor, Lincoln, NE). NEE was calculated as the sum of the measured $\mathrm{CO}_{2}$ eddy flux at the instrument height and the change in $\mathrm{CO}_{2}$ storage in the air layer between the instruments and the surface (Barr et al., 2006). Nighttime NEE values were rejected under calm conditions using a $\mathrm{u}^{*}$ threshold of $0.30 \mathrm{~m} \mathrm{~s}^{-1}$. Net Ecosystem Production (NEP) was estimated as -NEE assuming no losses via dissolved organic carbon. Finally, gaps in NEP were filled and NEP was partitioned into gross primary production GPP $\left(\mu \mathrm{mol} \mathrm{C} \mathrm{m}{ }^{-2} \mathrm{~s}^{-1}\right)$ and total ecosystem respiration $\mathrm{R}_{\mathrm{e}}\left(\mu \mathrm{mol} \mathrm{C} \mathrm{m} \mathrm{C}^{-2} \mathrm{~s}^{-1}\right)$ using the standard Fluxnet-Canada method (Barr et al., 2004).

\subsection{Environmental Variables}

Air temperature and relative humidity were recorded in the canopy at $6 \mathrm{~m}$ height with a Vaisala HMP45C probe. Soil temperature measurements were taken with Type$\mathrm{T}$ (copper-constan) thermocouples at two locations at a $10 \mathrm{~cm}$ depth below the living- 
moss layer and averaged together. Soil volumetric water content (VWC) was recorded at two locations at a $7.5 \mathrm{~cm}$ depth with Cambell Scientific CS615 Water Content Reflectometers and averaged together. Wind speed and wind direction were measured with an RM Young model 05103-10 wind monitor located at the top of the tower at a height of $26 \mathrm{~m}$. Precipitation was measured with a Geonor T-200B all-weather weighing precipitation gauge located on the roof of the hut at a height of $3.5 \mathrm{~m}$ above ground level.

\subsection{Data Analysis: Curve Fitting and Random Forest Models}

We applied the mechanistic equations for the relationships between VI's, SIF, GPP, and PAR at varying temporal scales by fitting curves to SIF/VI's and GPP as well as the light response curves of SIF and GPP. Fitting light response curves allowed us to extract information on $\mathrm{LUE}_{\mathrm{F}}$ and $\mathrm{LUE}_{\mathrm{P}}$ from the fit parameters following Equations 1, 5, and 6. All fitting was done using the fit function within Matlab's curve fitting toolbox (MATLAB, 2021). Fit parameters and goodness of fit statistics ( $\mathrm{R}^{2}$ values) were also extracted using the fit function. All fitted equations are provided within the results and in figure captions where relevant.

We explored the significance of environmental variables as predictors for SIF and GPP at diurnal and seasonal timescales using random forest regression models. We used Matlab's TreeBagger to create four random forest regression models to predict both SIF and GPP at half-hourly and daily resolutions (HH-SIF, HH-GPP, Daily-SIF, Daily-GPP) thereby testing the significance of environmental predictors across diurnal and seasonal scales respectively. Random forest models were chosen due to their high degree of interpretability as well as their non-parametric nature, making them more suitable for approximating nonlinear relationships in complex systems (Breiman, 2001). Both SIF and GPP models were initially trained using the following half-hourly or daily averaged environmental variables as features: PAR, precipitation, soil volumetric water content (VWC) at $7.5 \mathrm{~cm}$, soil temperature at $10 \mathrm{~cm}$, air temperature at canopy height $(6 \mathrm{~m})$, relative humidity at canopy height $(6 \mathrm{~m})$, friction velocity $\left(\mathrm{u}^{*}\right)$, wind speed and wind direction above canopy $(26 \mathrm{~m})$, and one column of random numbers for reference. Each model was built with the following sized datasets, which reflect the number of available data during the overlapping collection period, July 24, 2019 to Dec 31, 2020: HH-SIF (25,296), HH-GPP (25,296), Daily-SIF (527), Daily-GPP (527). All 4 models had 100 decision trees, used $70 \%$ of data to train, and were sampled without replacement. We checked model 
performance using the $\mathrm{R}^{2}$ and out-of-bag (OOB) scores and assessed the predictive power of each feature using the OOB predictor importance estimates (Breiman, 2001). The OOB scores and predictor importance estimates evaluate model performance on unseen data, thereby testing the models generalizability. We then tested each model by systematically removing the lowest performing predictor, re-training the model, and comparing the $\mathrm{R}^{2}$ and OOB scores (Section 3.2). This process was repeated until only one predictor variable remained. The highest performing random forest model for daily average GPP (5 predictors, Figure 4) was used to predict GPP from September 9, 2018 (the start of PhotoSpec measurements) to July 24, 2019 (the start of GPP data) and is presented for visualization in Figure 2. Modeled GPP was not used in any additional analysis - merely to illustrate approximate GPP prior to the start of flux-tower measurements.

\section{Results}

\subsection{SIF and VIs as proxies for GPP from half-hourly to seasonal scales}

PhotoSpec data (far-red SIF, CCI, PRI, NIRv, NDVI) and flux tower GPP highlight both the dynamic nature of evergreen photochemistry at weekly to seasonal scales at the SOBS site, as well as the utility of remotely sensed measures for explaining seasonal trends in GPP (Figure 2).

GPP, PAR, and air temperature exhibit patterns consistent with historical data at SOBS (Liu et al., 2019) with the growing season extending from approximately late May to early September and the peak of GPP in late July to early August for both 2019 and 2020. Winter dormancy occurs approximately November through March (Pierrat et al., 2021). PAR values increase in spring, well before the start of the growing season, and explain some of the daily to weekly variability in GPP during the growing season (Figure 2f). Air temperature above $0^{\circ} \mathrm{C}$ is associated with both the onset (Pierrat et al., 2021) and cessation of photosynthesis (Figure 2g).

Greenness-based vegetation indices NIRv and NDVI show strong responses to snow cover and poor ability to track the seasonal cycle of tower-based (black line with error bars) and modeled (gray line, Section 2.5) GPP (Figure 2d,e). NIRv remains near constant during fall, spring, and summer, despite the strong seasonal cycle of GPP $\left(\mathrm{R}^{2}=\right.$ -0.04 for 5-day moving mean). However, NIRv shows a small gradual increase over the growing season, which we interpret as consistent with changes in canopy structure and 


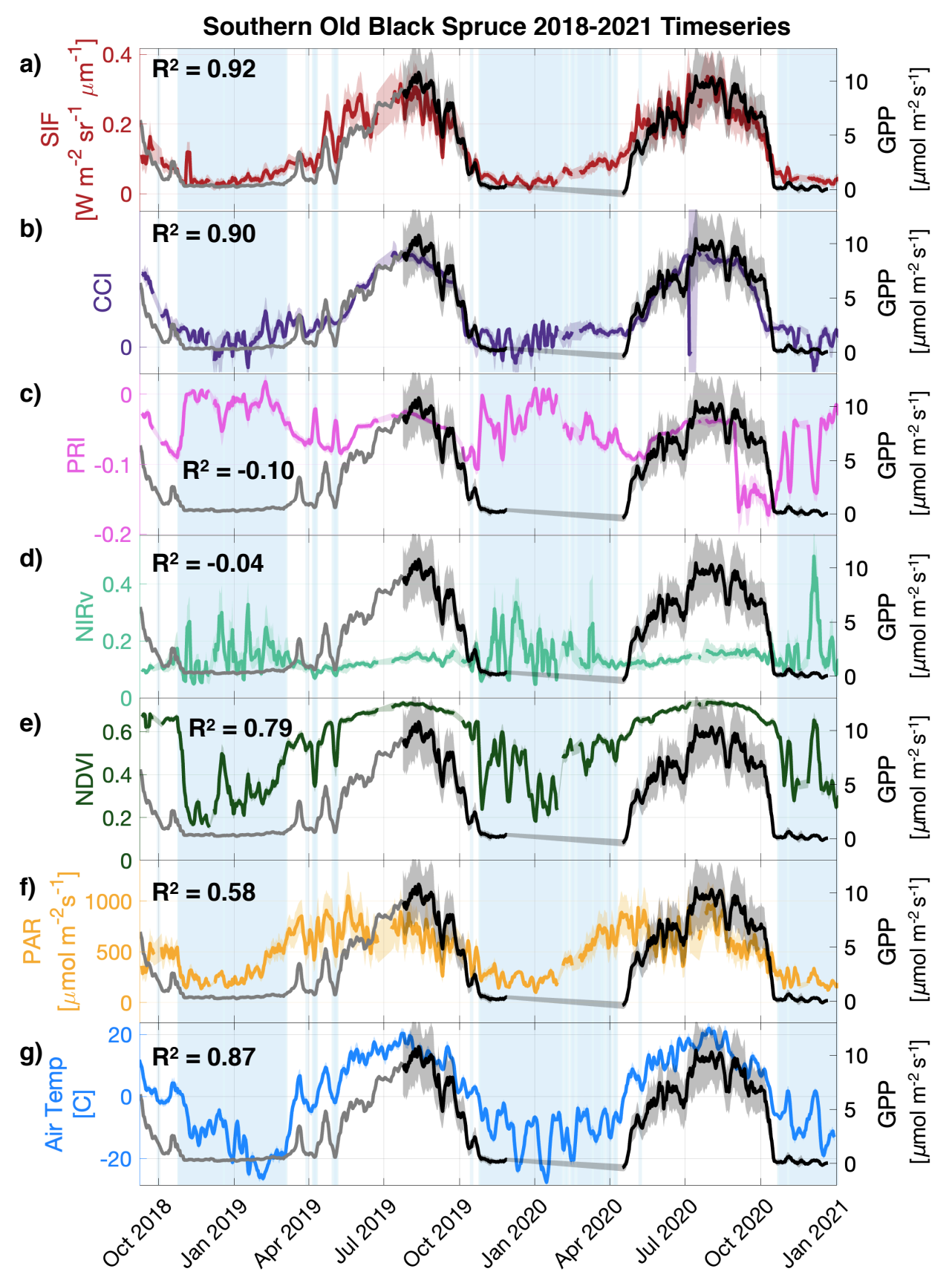

Figure 2. a) SIF, b) CCI, c) PRI, d) NIRv, and e) NDVI measurements from PhotoSpec, f) PAR above the canopy $(26 \mathrm{~m})$, and g) air temperature at canopy height $(6 \mathrm{~m})$ compared with tower-based GPP data for the study period. Solid lines are 5-day moving means of daily averaged data. Shaded error bounds are the standard deviation of diurnal variability. The gray GPP line with no shaded area is the 5-day moving mean of the Daily-GPP random forest model's predicted GPP. $\mathrm{R}^{2}$ values are the Pearson correlation coefficients between the 5-day moving means of tower-based GPP and the plotted variable. All $\mathrm{R}^{2}$ values were statistically significant with p-values $<0.005$. Light blue background regions are days with snow cover on the canopy as identified by phenocam images. $-14-$

This article is protected by copyright. All rights reserved. 
variability in $f_{\text {esc }}$ (Zeng et al., 2019; Badgley et al., 2019). Additionally, NIRv exhibits strong, random, variability over winter due to snow cover or other confounding effects. NDVI shows a stronger correlation with GPP $\left(\mathrm{R}^{2}=0.79\right)$. However, changes in NDVI are predominantly due to a strong snow response of the NDVI signal, notably in early spring and over winter. For the same reason, NDVI increases earlier and remains elevated longer than GPP. Over summer, NDVI shows a slight seasonal curvature with peak NDVI matching peak GPP. Prior work has shown that NDVI tracks photosynthetic phenology well in deciduous temperate ecosystems (H. Yang et al., 2017), but not in evergreen needleleaf forests (Magney, Bowling, et al., 2019) where canopy structure and crown architecture have a minor and de-coupled influence on carbon uptake (Pappas et al., 2020). A species-specific analysis confirms that in the SOBS mixed-stand forest, changes in NDVI and NIRv predominantly reflect changes in deciduous larch, while evergreen NDVI and NIRv remain largely invariant (Pierrat et al., 2021).

CCI and PRI track the seasonal cycle of GPP well but do not exhibit sharp changes on the scale of days to weeks that we observe with GPP (Figure 2b,c). During spring, CCI and PRI are less responsive to variability in modeled (2019) and tower-based (2020) GPP, and show a delay in the timing of their increase compared with GPP (40 days in 2019, 29 days in 2020) (Pierrat et al., 2021). Over summer, CCI peaks in early July, prior to maximum GPP in both 2019 and 2020. PRI shows a closer agreement with the summer peak of GPP, but shows less variability over the summer months and is less effective at tracking the seasonal trends in GPP. In fall, CCI shows good agreement with the seasonal downregulation of photosynthesis, while PRI decreases prior to and more rapidly than GPP. Over winter, CCI hovers around zero with a few periods of stronger variability below zero. This is potentially due to a small response to snow cover. PRI also shows strong responses to snow over winter with increased values during periods of snow cover (Pierrat et al., 2021). This makes the interpretation of wintertime PRI values significantly more challenging.

SIF tracks tower-based and modeled GPP well, does not show strong responses to snow, and shows similar or stronger correlations with GPP than all other vegetation indices and environmental variables $\left(\mathrm{R}^{2}=0.92\right)$ (Figure $2 \mathrm{a}$ ). In summer, daily to weekly variability in SIF closely tracks variability in tower-based GPP, most notably at the end of September 2019 and June and July of 2020. In fall, SIF shows the same general decline as GPP. Over winter, unlike GPP, SIF does not go to zero but remains low and less 
variable compared to its overall seasonal change and the daily to weekly variability over summer. In spring, SIF increases prior to changes in GPP for both years. This is consistent with Magney, Bowling, et al. (2019) and is explored further in Sections 3.3 \& 4.2.

Because SIF, CCI, and NDVI showed the strongest correlations with GPP at a daily 5 -day moving mean resolution $\left(\mathrm{R}^{2}=0.92,0.90,0.79\right.$ respectively), we explored their relationships to GPP at varying temporal resolutions in more detail (Figure 3). Fitted equations and parameters are summarized in Table S1. Correlations between SIF, CCI, or NDVI and GPP at monthly, daily, and half-hourly resolutions highlight the strengths and limitations of each index.

At a monthly resolution, linear fits of SIF (a), CCI (d), and NDVI (g) all show strong correlations with tower-based GPP $\left(\mathrm{R}^{2}=0.94,0.95,0.82\right.$ respectively). At a daily resolution, a linear fit of SIF shows the strongest correlation with GPP $\left(\mathrm{R}^{2}=0.79\right)$, followed by CCI $\left(\mathrm{R}^{2}=0.75\right)$ and NDVI $\left(\mathrm{R}^{2}=0.56\right)$. A non-linear fit between SIF and GPP did not improve $\mathrm{R}^{2}$ values $\left(\mathrm{R}^{2}=0.78\right.$ for Equation 8 , Figure $\left.\mathrm{S} 1\right)$.

At a half-hourly resolution, SIF, fit with Equation 8, shows the strongest correlation $\left(\mathrm{R}^{2}=0.64\right)$, while linear fits of CCI and NDVI both show low correlations $\left(\mathrm{R}^{2}=\right.$ 0.02, 0.30 respectively). At a half-hourly resolution, SIF increases while GPP saturates at high PAR, which leads to a higher degree of non-linearity (Figures 3c, S1c, S2). A linear fit for half-hourly SIF and GPP data resulted in a similar $\mathrm{R}^{2}$ value $\left(\mathrm{R}^{2}=0.62\right.$ for linear, Figure S1c). However, plotting summer data shows that there is in fact a high degree of non-linearity associated with high PAR values (Figure S2). CCI and NDVI primarily reflect slower seasonal changes in leaf pigments and canopy structure, and therefore do not track the strong variability of GPP with changes in PAR at half-hourly and daily resolutions. In contrast, SIF and GPP both show variability within each season associated with changes in PAR (Figure S1).

In summary, when measured at higher temporal frequencies, the relationship between GPP and all remotely sensed products decreases and the relationship between SIF and GPP becomes increasingly non-linear. Despite this non-linearity, SIF significantly outperforms all other remotely sensed indices as a proxy for GPP. This non-linearity is explored in further detail in Sections 3.3 \& 4.2. 

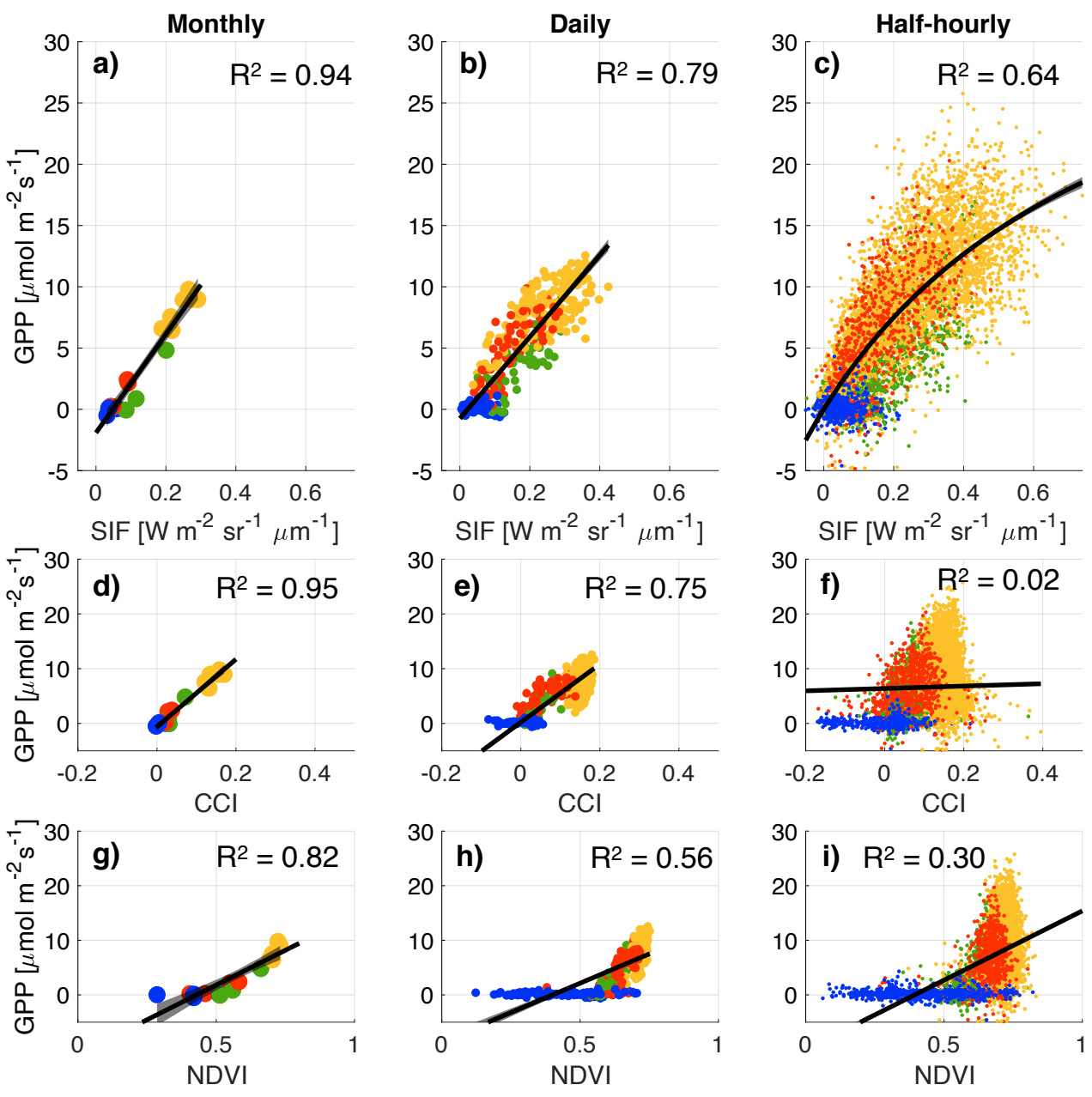

Winter

Spring Summer

Fall

Figure 3. The relationships between SIF, CCI, or NDVI, and GPP at monthly, daily, and half-hourly resolutions. Solid black lines are linear fits except c) half-hourly GPP vs. SIF which is based off Equation 8. Shaded gray regions are the $95 \%$ non-simultaneous functional prediction bounds for the fit. $\mathrm{R}^{2}$ values are the degree-of-freedom adjusted coefficient of determination of the fit. Fitted parameters and equations are summarized in Table S1. Winter, Spring, Summer, and Fall are defined as October 24-April 18, April 19-May 25, May 26-September 15, and September 16-October 23 respectively.

This article is protected by copyright. All rights reserved. 


\subsection{Environmental drivers of SIF and GPP at half-hourly and daily res- olutions}

We explored the explanatory power of several environmental parameters using random forest models to determine which variables had the best predictive capacity for SIF and GPP at diurnal and seasonal timescales. All four random forest models (HH-SIF, HH-GPP, Daily-SIF, Daily-GPP) had good performance and high generalizability with all predictors included and when only three predictors were included (Figure 4a).

After systematically eliminating low importance predictors, the three most important predictors for all four models were PAR, soil temperature, and air temperature (Figure 4b). HH-SIF and HH-GPP showed PAR as the most important predictor. However, using PAR as the only predictor showed a notable decrease in performance (HH-SIF OOB $\mathrm{R}^{2}=0.61$ and HH-GPP OOB $\mathrm{R}^{2}=0.31$ ). These results highlight the fact that variability in SIF cannot simply be explained by changes in PAR. Thus, while the variability in both SIF and GPP over the course of a day (half-hourly resolution) is mostly driven by variability in PAR, on a seasonal scale, SIF and GPP are regulated by other environmental factors related to temperature.

Daily-SIF and GPP models confirm this seasonal temperature dependence, with air temperature being the most important predictor for both models. Going from three to two predictors, Daily SIF and GPP showed slight decreases in performance (OOB $\mathrm{R}^{2}$ of 0.94 to 0.92 and 0.89 to 0.87 respectively) and diverged in predictor importance rankings. With two predictors, daily SIF was best predicted using PAR and air temperature, while daily GPP was best predicted using air and soil temperature. Using only one predictor, both daily SIF and GPP were primarily driven by air temperature.

The only notable drops in $\mathrm{R}^{2}$ and OOB $\mathrm{R}^{2}$ scores before 3 predictors were reached occurred when removing wind direction from the HH-GPP model $\left(\mathrm{OOB} \mathrm{R}^{2}=0.72\right.$ to 0.69 going from 5 to 4 predictors, Figure 4a) This change was not observed in the HHSIF or Daily-SIF models. While wind direction does not impact SIF, it determines the part of the forest that is in the eddy-covariance footprint to which GPP is sensitive (Chu et al., 2021). The change in $\mathrm{R}^{2}$ values thus highlights the importance of considering the GPP footprint in heterogeneous and mixed-species canopies (such as the SOBS site) (Chu et al., 2021). 
Random forest model performance and predictor importances

a)

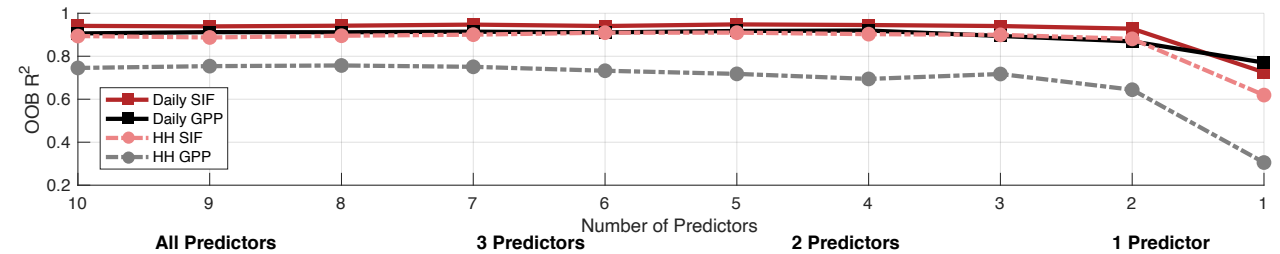

b)
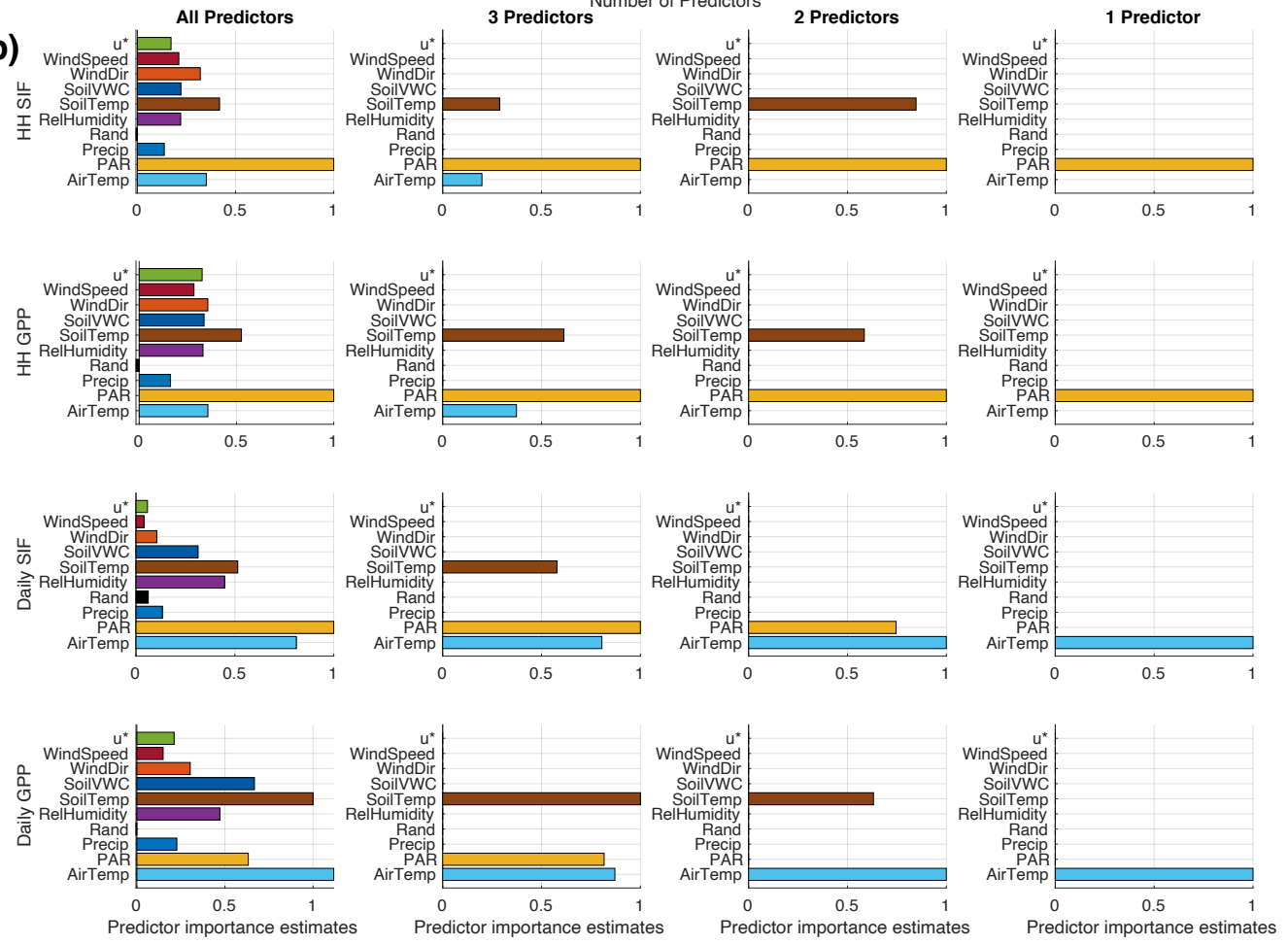

Figure 4. Random forest model performance evaluation and predictor importance estimates for all four models: (half-hourly) HH-SIF, HH-GPP, Daily-SIF, Daily-GPP. a) Shows OOB R ${ }^{2}$ values for all four models with decreasing numbers of predictors included. b) is the predictor importance estimates for all four models with all predictors included (ten total), three, two, and one predictor included. Predictor importance estimates are normalized to a scale from 0-1 based on the highest performing predictor. 


\subsection{Light responses of SIF and GPP, and the impact of canopy struc- ture on SIF}

Monthly light response curves of SIF and GPP (Figure 5) and $f_{e s c}, \mathrm{LUE}_{\mathrm{F}}$, and LUEP (Figure S3), illustrate the diurnal and seasonal dynamics of SIF and GPP and highlight why SIF is an effective proxy for GPP despite their non-linear relationship. Figure 6 summarizes the monthly physical $\left(f_{\text {esc }}\right)$ and ecophysiological $\left(\mathrm{LUE}_{\mathrm{F}}, \mathrm{LUE}_{\mathrm{P}}, \mathrm{GPP}_{\max }\right.$, c) parameters that determine the relationship between SIF and GPP as fitted in Figure 5 or averaged monthly. Fitted equations and parameters are summarized in Table S3.

Figure 5a shows the impact of APAR on $f_{\text {esc }}$ while Figure 6a summarizes the monthly average $f_{\text {esc }}$ values. Winter $f_{\text {esc }}$ values are heavily influenced by the snow response of NIRv (Figure 2d) and therefore make the data more difficult to interpret. When we ignore $f_{e s c}$ during snow covered months, the seasonal change in $f_{e s c}$ is approximately $20 \%$ (Figure 6a). $f_{\text {esc }}$ shows a slight decrease at high APAR values over the summer months, which is most pronounced in June and July (Figure 5a). The sensitivity of $f_{\text {esc }}$ to high APAR values thus impacts the light response of SIF shown in Figure 5b.

Monthly light response curves of SIF in Figure 5b were determined with a linear fit based on Equation 1 (SIF $=a \times \mathrm{APAR}$ ). Thus, the fit factor $a$ represents average $L_{U E} \times f_{\text {esc }}$ for each month. Within each month the light response of SIF shows a slight curvature at high APAR values. This leveling off is most noticeable in April, May, June, August, and September. We attribute the curvature in the SIF light response curve to variations in $f_{\text {esc }}$ at a high temporal resolution under high light conditions, as shown in Figure 5a. When we correct for the effects of $f_{\text {esc }}$ by calculating $\mathrm{SIF}_{\text {total }}$, the leveling off of SIF at high light is no longer observed (Figure 5c), with the exception of May where rapid changes during the spring transition create additional confounding effects. Light responses of half-hourly $\mathrm{LUE}_{\mathrm{F}}$ values calculated following Equation $1\left(\mathrm{LUE}_{\mathrm{F}}=\frac{\mathrm{SIF}}{f_{e s c} * \mathrm{APAR}}\right)$ show a subtle decline at high APAR values (Figure S3b), however, it is significantly smaller than the decline in $\mathrm{LUE}_{\mathrm{P}}$ (Figure S3c) and the light saturation observed with GPP (Figure $5 d)$.

Light response curves of $\mathrm{SIF}_{\text {total }}$ in Figure $5 \mathrm{c}$ were calculated using a linear fit after correcting SIF for variations in $f_{e s c}\left(\mathrm{SIF}_{\text {total }}=\frac{\mathrm{SIF}}{f_{\text {esc }}}=a \times \mathrm{APAR}\right)$. Thus, the fit parameter $a$ represents the monthly average $\mathrm{LUE}_{\mathrm{F}}$. Fitted values for $\mathrm{LUE}_{\mathrm{F}}$ from Fig- 
a)

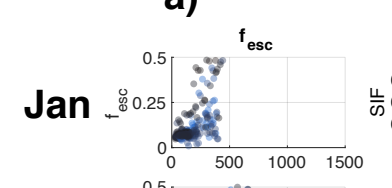

b)

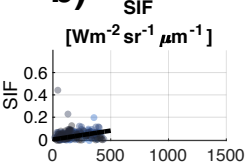

Feb
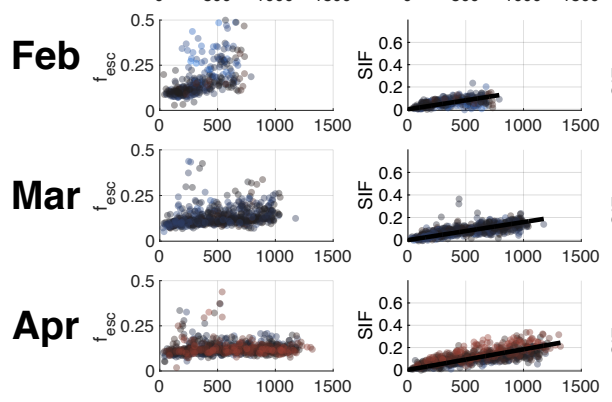

c)

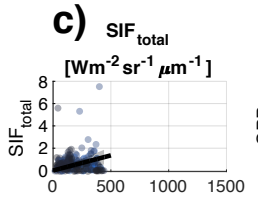

d)
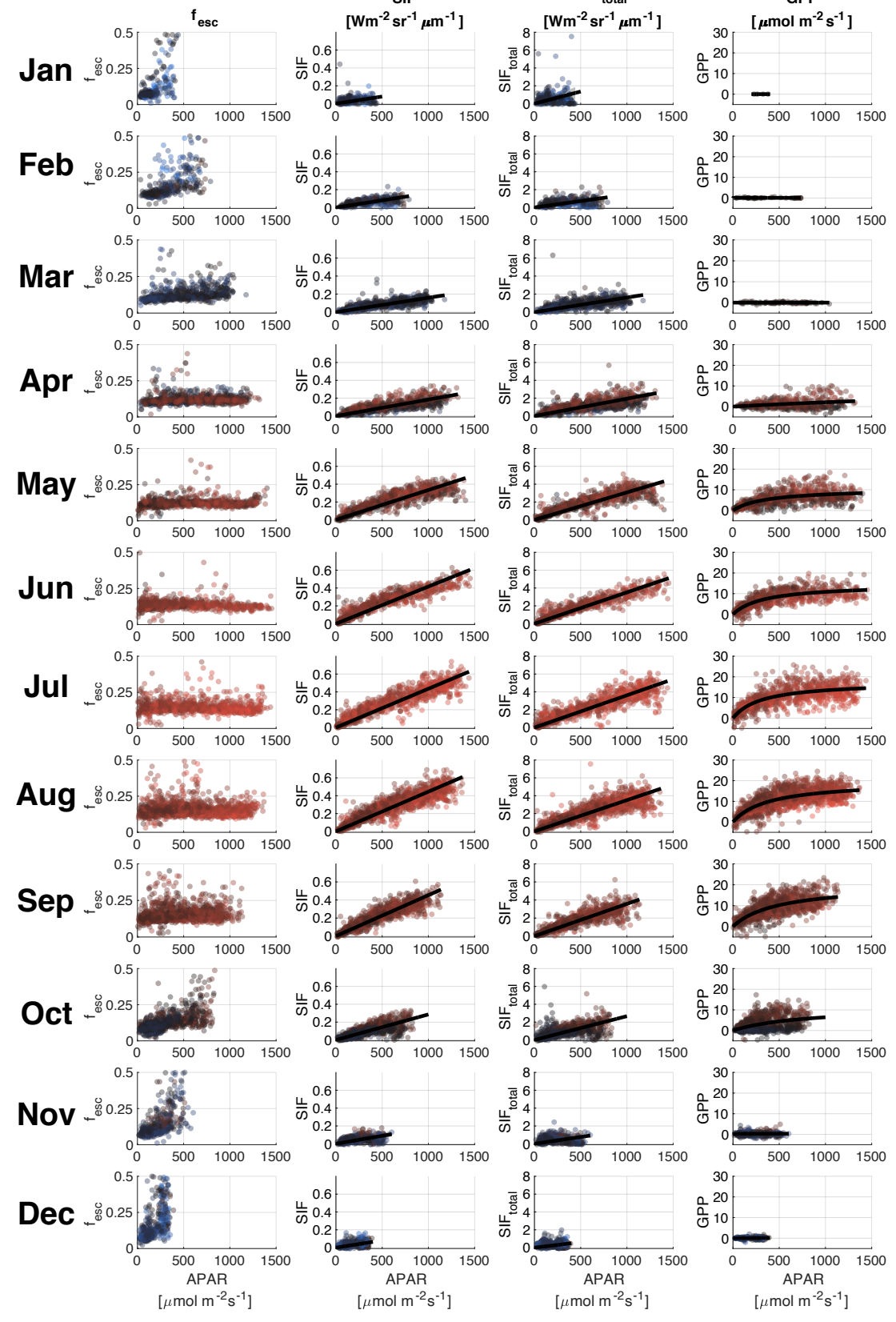

Temperature $[\mathrm{C}]$

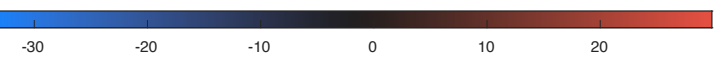

Figure 5. Half-hourly data with fitted curves. Column a) $f_{\text {esc }}$ calculated from Equation 4 plotted against APAR b) light response curves of SIF with a linear fit, c) light response curves of $\mathrm{SIF}_{\text {total }}$ calculated from Equation 3 with a linear fit, d) light response curves of GPP fitted with GPP $=\frac{\text { GPP }_{\max } \times \mathrm{APAR}}{c+\mathrm{APAR}}$ (derived from Equations $5 \& 6$ ). Fitted equations and parameters are summarized in Figure 6 and Table S2. 
Fit parameters from monthly SIF and GPP light responses $\left(\right.$ LUE $\left._{\mathrm{F}} \mathrm{GPP}_{\max } \mathrm{c}\right)$ and monthly average $\mathrm{f}_{\mathrm{esc}}$ and $\mathrm{LUE}_{\mathrm{P}}$
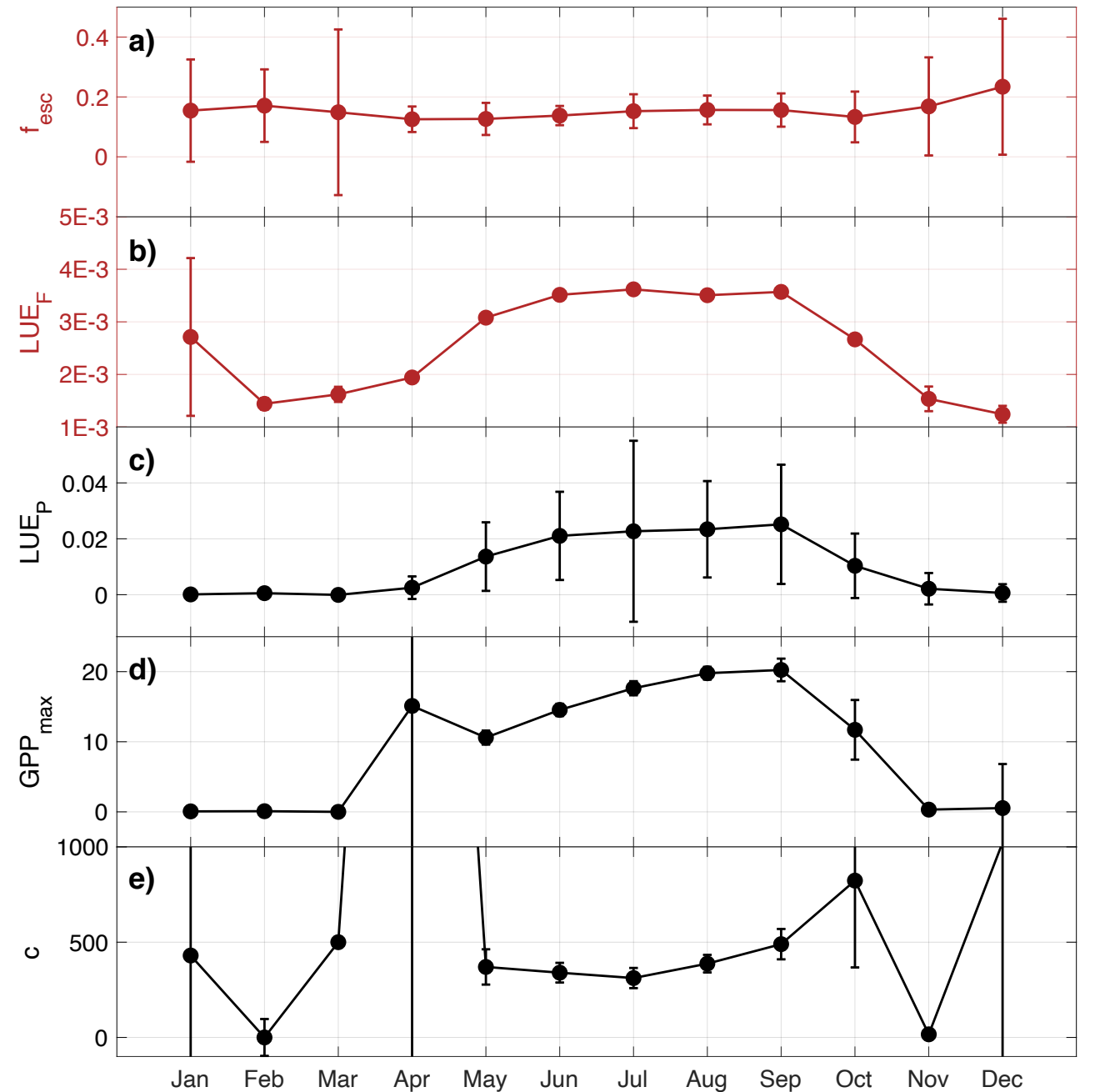

Figure 6. Values determined from Figures 5 and S3. Numerical values for b), d), and e) are reported in Table S2. a) $f_{\text {esc }}$ values are monthly averaged $f_{\text {esc }}$ as determined with Equation 4 , b) $\mathrm{LUE}_{\mathrm{F}} \frac{\left[\mathrm{Wm}^{-2} \mathrm{sr}^{-1} \mu \mathrm{m}^{-1}\right]}{\left[\mu \mathrm{molm}^{-2} \mathrm{~s}^{-1}\right]}$ values are determined from the $\mathrm{SIF}_{\text {total }}$ light response curves in Figure $5 \mathrm{c}$, c) $\mathrm{LUE}_{\mathrm{P}}$ [unitless] values are monthly averaged LUEP (Figure S3) calculated following Equation 5 as $\mathrm{LUE}_{\mathrm{P}}=\frac{\mathrm{GPP}}{\mathrm{APAR}}$. d) $\mathrm{GPP}_{\max }\left[\mu \mathrm{mol} \mathrm{m} \mathrm{s}^{-2}\right]$ and e) $c\left[\mu \mathrm{mol} \mathrm{m}^{-2} \mathrm{~s}^{-1}\right]$ are determined from the GPP light response curves in Figure $5 \mathrm{~d}$ (GPP $=\frac{\text { GPP max } \times \text { APAR }}{c+\mathrm{APAR}}$, derived from Equations 5\&6). Error bars in a)and c) are the standard deviations of $f_{\text {esc }}$ and $\mathrm{LUE}_{\mathrm{P}}$ within each month and in b), d), and e) they are the $95 \%$ confidence intervals of fitted values. Anomalous values with high fit errors go outside the bounds of the plot but exact values can be found in Table S2.

This article is protected by copyright. All rights reserved. 
ure $5 \mathrm{c}$ are summarized in Figure $6 \mathrm{~b}$. Over the course of the year, correcting for $f_{\text {esc }}$ does

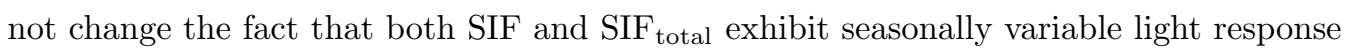
curves and thus, structural and illumination effects cannot fully explain the increase in summer SIF. Seasonal variability in $\mathrm{LUE}_{\mathrm{F}}$ (as calculated from the fitted curves in Figure 5c) shows a strong downregulation, but non-zero values, over winter and a gradual increase towards spring (Figures 5b-c \& 6b)This winter light response explains the early spring increase in SIF prior to changes in GPP observed in Figure 2a. This is further explored in Section 4.2. In summary, the influence of $f_{e s c}$ is important for SIF at a high temporal resolution when high APAR values create more variable radiative conditions, while the influence of $\mathrm{LUE}_{\mathrm{F}}$ is more dominant over the seasonal cycle.

Figures 5d and S3c highlight both the light saturation of GPP during the growing season as well as its seasonal up and downregulation. Light response curves of GPP in Figure 5d are a non-linear least squares fit following Equations 5 and $6\left(\mathrm{GPP}=\frac{\mathrm{GPP} \max \times \mathrm{APAR}}{c+\mathrm{APAR}}\right)$ and $\mathrm{LUE}_{\mathrm{P}}$ in Figure $\mathrm{S} 3 \mathrm{c}$ is calculated following Equation $5\left(\mathrm{LUE}_{\mathrm{P}}=\frac{\mathrm{GPP}}{\mathrm{APAR}}\right) \cdot \mathrm{LUE}_{\mathrm{P}}$ is variable over shorter timescales due to changes in APAR Equations 5,6, Figure S3c and seasonally variable due to the seasonal changes in photosynthetic capacity. The response of $\mathrm{LUE}_{\mathrm{P}}$ to APAR is shown in Figure 5d as the curvature of each GPP light response curve within a particular month at high APAR values and in Figure S3c as the curvature in the light response of $\mathrm{LUE}_{\mathrm{P}}$. The seasonal light response of GPP shows maximum saturation values $\left(\mathrm{GPP}_{\max }\right)$ over summer and minimum values over winter (Figures $5 \mathrm{~d} \& 6 \mathrm{c}, \mathrm{d})$, with the exception of April where rapid changes during the spring transition led to poor fit statistics. This is in good agreement with the seasonal cycle of monthly averaged $\mathrm{LUE}_{\mathrm{P}}$ (Figure 6c). Seasonal changes in $\mathrm{GPP}_{\max }$ and $\mathrm{LUE}_{\mathrm{P}}$, which reflect the seasonal cycle of GPP, are driven by the seasonal up and downregulation of photosynthesis and sustained photoprotection over winter. The light response curves of GPP and LUE $_{\mathrm{P}}$ show the highest degree of non-linearity over summer, while in winter, spring, and fall, linear fits performed nearly as well as the fitted equation. This is also reflected in the fit parameter $c$ (Figure 6e) which shows a small seasonal cycle with minimum values over summer (excluding Jan, Feb, Mar, Nov, Dec when GPP is essentially 0 and there is insufficient light for saturation). Lower $c$ values represent a more pronounced curvature in the light response of GPP over summer. This may reflect the fact that non-summer fits involve a smaller range of APAR values and thus do not receive sufficient light to saturate photosynthesis. We attribute the seasonal variation in $c$ as likely due to temper- 
ature dependencies. In addition, water limitations or other environmental stresses may impact $c$ over shorter temporal resolutions. Seasonal asymmetry in $c$ may be caused by differences in temperature and water availability between the start and end of the growing season.

Seasonal variations in $\mathrm{GPP}_{\max }$ and monthly average $\mathrm{LUE}_{\mathrm{P}}$ largely agree with the seasonal variations in $\mathrm{LUE}_{\mathrm{F}}$, however, they exhibit some important differences (Figure 6b,c,d). In particular, $\mathrm{LUE}_{\mathrm{F}}$ slightly increases in spring prior to significant changes in

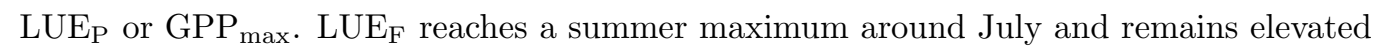
at a near constant value from June through September. On the other hand, GPP $\max _{\text {ax }}$ continues to increase over the summer, peaking in September before decreasing for winter. These subtle changes in shape lead to a seasonally variable relationship between SIF and GPP.

Figure 7a\&b shows the relationships between SIF-GPP and SIF $_{\text {total-GPP fitted }}$ monthly to half-hourly data. Fitted equations and parameters are summarized in Table S3. Over the winter months, the relationships between SIF or $\mathrm{SIF}_{\text {total }}$ and GPP appear more linear, despite being fit with the non-linear Equation 8. Over summer, the nonlinear relationship between SIF or $\mathrm{SIF}_{\text {total }}$ and GPP becomes more pronounced. This can be attributed to the fact that curvature in the light response curve of GPP is most pronounced over summer (Figure 5d), and thus shows up more prominently in the SIFGPP relationship. We observe a higher degree of non-linearity in the $\mathrm{SIF}_{\text {total-GPP re- }}$ lationship (Figure 7b) than the SIF-GPP relationship (Figure 7a), with the exception of July which can be attributed to a poor overall fit (Figure 7b, Table S3). The curvature of the SIF light response due to changes in $f_{\text {esc }}$ works to linearize the SIF-GPP re-

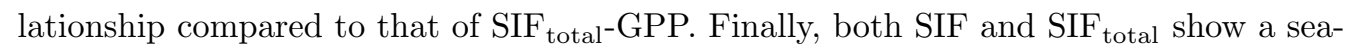
sonally variable relationship with GPP. We attribute this seasonal variation to the small light response of SIF over winter and slight differences in the seasonal changes in $\mathrm{LUE}_{\mathrm{F}}$ and $\mathrm{GPP}_{\max }$ (Figure 6).

\section{Discussion}

\subsection{SIF as a proxy for GPP, and relation to other VIs}

Our results highlight SIF as a more effective and comprehensive proxy for GPP than existing vegetation indices from half-hourly to monthly temporal scales in a boreal ecosys- 

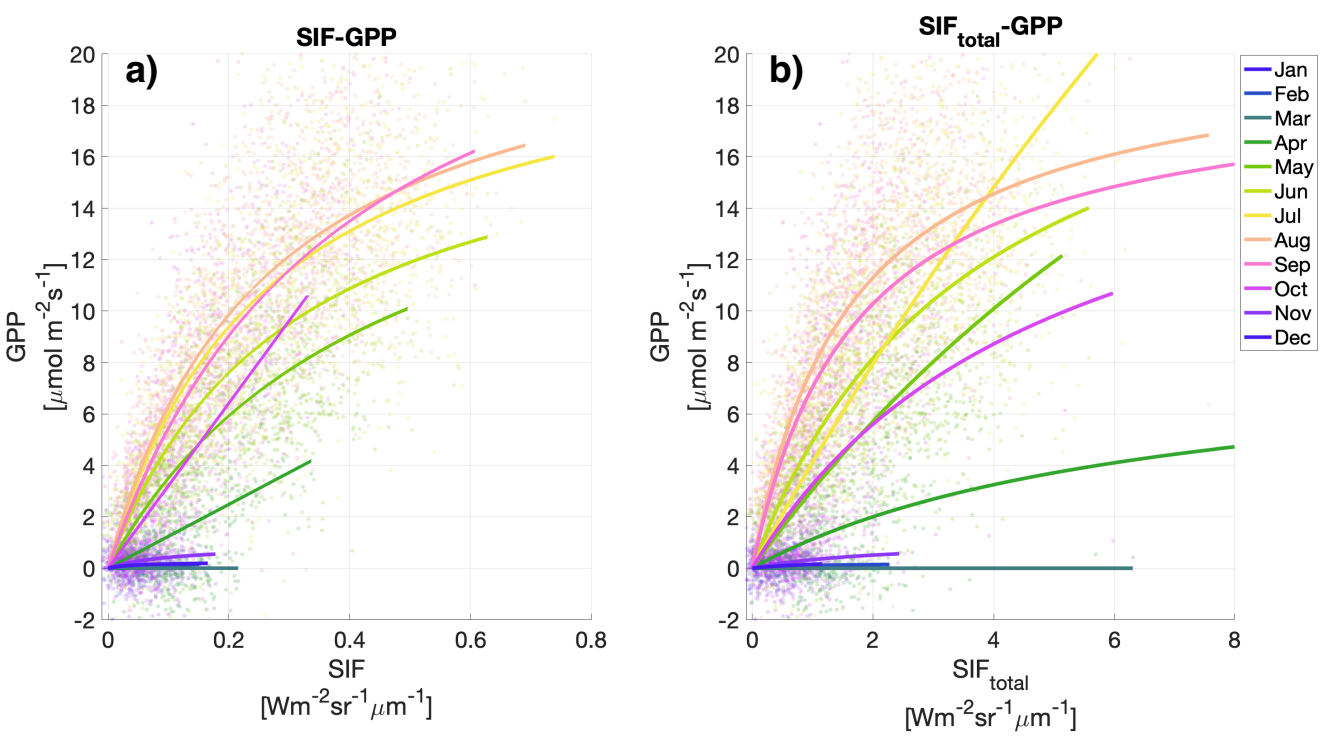

Figure 7. Monthly fitted curves to half-hourly data based on Equation 8 for a) SIF-GPP

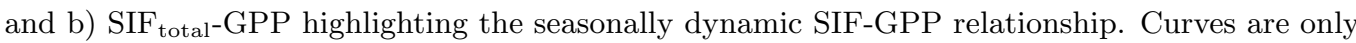
plotted within the data range for that month. Scatter points are half-hourly values.

tem. This can be attributed to the close link between SIF and electron transport rate (ETR, the product of efficiency of photochemistry and absorbed light by chlorophyll), the first step in photosynthetic carbon assimilation ( $\mathrm{Gu}$ et al., 2019). Our results show the correlation between SIF and GPP strengthens with longer temporal averaging windows (Figure 3). Additionally, if one considers the inherent non-linearity in the SIF-GPP relationship (Section 4.2), SIF significantly outperforms other remotely sensed metrics as a proxy for GPP. Finally, SIF shows no strong responses to snow cover - an important consideration for boreal ecosystems (Figures $2 \& 3$ ).

Vegetation indices show substantially decreased effectiveness over shorter temporal scales (daily, half-hourly) compared with SIF (Figures $2 \& 3$ ). The second most effective proxy for GPP (after SIF) was CCI. CCI reflects the ratio of chlorophyll:carotenoids, which change seasonally to support sustained NPQ and the regulation of photosynthesis (Gamon et al., 2016). These bulk pigment ratios are not expected to change at a daily time resolution (Gamon et al., 2016) and are therefore unable to capture the dynamic nature of GPP at sub-seasonal temporal resolutions. CCI is thus a useful metric for satellite observations with only one sample per day for tracking the seasonality of GPP and 
sustained NPQ, with a few caveats. Our observations show that CCI reaches a maximum over summer, prior to maximum GPP (Figure 2b). The fall increase in carotenoid pigments to support sustained photoprotection over winter may occur prior to fall cessation of GPP due to the inter-conversion between xanthophyll pigments. Furthermore, we observe only small variations in CCI during the spring transition which suggests a potential reactivation of photosynthesis, prior to the spring decrease in carotenoid pigments (Pierrat et al., 2021). Therefore, CCI is a good metric for tracking general seasonality in evergreen systems and can provide important insights into plant's LUE $E_{P}$. However, it has limited accuracy for determining spring onset and fall cessation dates and for tracking GPP at finer (daily/half-hourly) resolutions. These subtle differences may indicate a mismatch between the timing of optimal photosynthetic capacity (peak CCI) and optimal environmental, structural, and physiological conditions (peak GPP).

Our results imply that SIF is not solely proportional to the light absorbed by chlorophyll but is also responding dynamically to seasonal variation in NPQ through changes in $L_{U E}$. The yield of fluorescence and the yield of photochemistry are both impacted by PQ and NPQ (Porcar-Castell et al., 2014). Prior work at the leaf level has shown that under high light levels, when there is significant induction of NPQ, the yield of fluorescence and the yield of photochemistry are proportional (Porcar-Castell et al., 2014; Van Der Tol et al., 2014). Our results show that at the canopy scale, seasonal changes in LUEF do indeed co-vary with seasonal changes in $\mathrm{LUE}_{\mathrm{P}}$ (Figures 5, 6, \& S3). The performance of the HH-SIF random forest model decreased considerably when only PAR was included (Figure 4) and the Daily-SIF random forest model showed air temperature as the strongest predictor. This confirms the fact that PAR alone is insufficient for explaining the observed variation in SIF, even at a half-hourly resolution.

Air temperature is a useful predictor of sustained NPQ in temperate evergreen ecosystems and sustained NPQ is responsible for shaping the seasonal patterns of SIF (Raczka et al., 2019). Our results provide empirical evidence to support this explanation because both daily average SIF and GPP were best predicted by air temperature (Figure 4). We found that accounting for changes in $f_{\text {esc }}$ over the course of the season was also insufficient for explaining the seasonal up and downregulation of fluorescence (Figure 5). We found that $f_{\text {esc }}$ only varied $\sim 20 \%$ over the course of the season, whereas changes in LUEF were significantly greater ( $350 \%$ increase over summer) (Figure 6$)$. This is particularly important in evergreen needle leaf systems but may not be true for cropping or decid- 
uous systems with high variance in canopy structure (and thus $f_{\text {esc }}$ ). The observed seasonal pattern in $\mathrm{LUE}_{\mathrm{F}}$ largely co-varied with the seasonal patterns of $\mathrm{LUE}_{\mathrm{P}}$ and $\mathrm{GPP}_{\max }$ making SIF an effective proxy for GPP (Figures $5 \& 6$ ).

We view the response of SIF to variations in light absorbed by chlorophyll not as a limitation of SIF as a proxy for GPP, but rather, a strength. SIF has a more dynamic light response than other remotely sensed products (CCI, NDVI, NIRv) and can therefore more effectively capture variations in GPP due to both common physical drivers (light absorbed by chlorophyll) and the ecophysiological connections between $\mathrm{LUE}_{\mathrm{F}}$ and $\mathrm{LUE}_{\mathrm{P}}$ based on the light reactions of photosynthesis.

\subsection{Dynamics between $\mathrm{LUE}_{\mathrm{F}}, \mathrm{LUE}_{\mathrm{P}}$, and $f_{e s c}$, and the convergence and divergence between SIF and GPP}

Over half-hourly temporal scales, when SIF and GPP are predominantly influenced by variations in PAR (Figure 4), the relationship between SIF and GPP will become nonlinear because $\mathrm{LUE}_{\mathrm{F}}$ is largely invariant with APAR compared with $\mathrm{LUE}_{\mathrm{P}}$ which exhibits strong saturation at high APAR values (Figures 5 \& S3). Within each month, LUE $E_{F}$ can show a subtle decline with increasing APAR (Figure S3b) which partially, but incompletely, linearizes the SIF-GPP relationship. This decline in $\mathrm{LUE}_{\mathrm{F}}$ may reflect short-term regulation of the photosynthetic system by rapidly reversible NPQ, although further work should investigate this in more detail. The decrease in $f_{e s c}$ at high APAR values also partially linearizes the relationship between SIF and GPP. Although the cause for the decrease in $f_{\text {esc }}$ at high APAR is unknown, we hypothesize that complex shading and illumination effects due to different sun geometries throughout the year may explain this decrease. Therefore, future work in this ecosystem and other evergreen needleaf ecosystems should therefore focus on further constraining the effects of $f_{\text {esc }}$ under a variety of viewing directions and illumination conditions.

Over longer temporal scales (seasonally), $\mathrm{LUE}_{\mathrm{P}}$ is predominantly driven by changes in $\mathrm{GPP}_{\max }$. When temporally averaging, the extreme PAR values that create the curvature in the light response of GPP become less important. Thus, due to the seasonal co-variation between $\mathrm{GPP}_{\max }$ and $\mathrm{LUE}_{\mathrm{F}}$ (Figure 6), the SIF-GPP relationship converges onto a linear relationship. 
Although the light saturation of GPP is the primary driver of divergence in the SIFGPP relationship, there are other stressors that vary seasonally and impact LUE $E_{P}$ and $\mathrm{LUE}_{\mathrm{F}}$, consequently impacting the relationship between SIF and GPP. Air and soil temperature, soil water content, and relative humidity were all important drivers of SIF and GPP identified in the random forest model optimization (Figure 4) and therefore may be driving divergence between $\mathrm{LUE}_{\mathrm{F}}$ and $\mathrm{LUE}_{\mathrm{P}}$ (and subsequently SIF and GPP). Furthermore, prior work has identified air temperature as an additional potential cause for non-linearity between SIF and GPP over the fall transition (Kim et al., 2021). This is not observed in our fall transition data. However, we observe some non-linearity between SIF and GPP at a daily resolution over summer (Figures $3 \&$ S2). We attribute this nonlinearity to the strong light saturation of GPP over summer and the dependence of $L_{U E}$ on APAR. This means that APAR is the predominant driver for non-linearity, although future work in this area is necessary to explore potential secondary sources of non-linearity.

Our results show a small light response of SIF during winter that has the potential to overestimate GPP in winter and early spring (Figures 5 \& 6 ). The wintertime light response of SIF may suggest low rates of wintertime photosynthesis that are not captured by flux tower measurements due to low signal-to-noise ratios. This may be possible if temperature is warm enough to thaw boles and allow trees to access small amounts of water stored in the stems (Ensminger et al., 2004; Bowling et al., 2018; Pierrat et al., 2021). However, we suggest that the observed early spring and winter light response of SIF may be attributed to photosystem I remaining active over winter while photosystem II shuts down more strongly (but not completely) with seasonal downregulation of photosynthesis (Öquist \& Huner, 2003; Bag et al., 2020; Porcar-Castell et al., 2008; PorcarCastell, 2011). This small amount of photosystem activity thus leads to a winter light response that does not reflect carbon assimilation. More work in this area is necessary to explore the nuances of wintertime SIF.

During the spring transition photosynthetic reactivation happens rapidly, in phases, and sometimes reversibly (Pierrat et al., 2021). Therefore, monthly or monthly averaged SIF and GPP data (Figures $5 \& 6$ ) are inadequate for accurately determining spring transition dates and higher temporal resolution data is necessary. A wintertime light response of SIF adds additional complexity to the use of SIF to determine start of season dates. For a more detailed look at the spring transition and how to effectively use SIF to evaluate the onset of photosynthesis in spring we refer readers to Pierrat et al. (2021). 
In order to account for additional potential non-linearities in the SIF-GPP relationship and adjust for the wintertime SIF light response, users of SIF should treat the SIF-GPP relationship as a seasonally dynamic variable as illustrated in Figure 7. This will help account for seasonally variable structural effects, as highlighted by Kim et al. (2021), as well as the seasonal differences between $L_{U E}$ and $L_{U E}$ and the wintertime SIF light response. A seasonally variant SIF-GPP relationship may also help account for additional non-linearities between SIF and GPP that are not due to the light saturation of GPP, including drought or temperature stress.

\subsection{Implications for Satellite Observations}

Spaceborne observations of SIF typically occur around midday and suffer from higher uncertainty under cloudy sky conditions (although this bias is less than typical vegetation indices) (Frankenberg et al., 2011; Parazoo et al., 2019; Köhler et al., 2018). Therefore, they are typically biased towards sunny sky and high light conditions. This bias may lead satellite based retrievals of SIF in boreal ecosystems to exhibit a stronger SIFGPP non-linearity. This will be exacerbated over summer when midday PAR often falls into the range where GPP is saturated and SIF continues to increase (Figures S1, S2, \& 5). Future work in this area may help us determine the impact of high light, sunny sky bias on satellite-derived SIF-GPP relationships. By introducing the non-linear function (Equation 8) for the relationship between SIF and GPP, users of satellite SIF data will more accurately describe the light saturation of GPP. Additionally, a seasonally dynamic SIF-GPP relationship allows users of SIF to better account for seasonal differences in $\mathrm{LUE}_{\mathrm{F}}$ and $\mathrm{LUE}_{\mathrm{P}}$.

\section{Conclusions}

This work provides a direct comparison between SIF and several other remote sensing metrics as proxies for GPP in the boreal forest and explains how the relationship between SIF and GPP becomes increasingly linear from half-hourly to monthly time scales.

We find that at daily to monthly resolutions, SIF shows a linear relationship with GPP and outperforms other commonly used vegetation indices (NDVI, NIRv, PRI, CCI) as a proxy for GPP. At a half-hourly resolution, the relationship between SIF and GPP becomes non-linear, as we would expect based on theory and the leaf level response of 
SIF and GPP to APAR. Nevertheless, SIF still provides a more effective proxy for GPP than other remote sensing metrics.

We use an entirely data-driven approach for separating out structural and physiological effects on SIF and GPP and the relationship between the two. The dynamics between $\mathrm{LUE}_{\mathrm{P}}, \mathrm{LUE}_{\mathrm{F}}$, and $f_{\text {esc }}$ dictate the nature of the relationship between SIF and GPP at varying temporal scales. At a half-hourly resolution, APAR is the primary driver of both SIF and GPP. Therefore, non-linearity between SIF and GPP at a half-hourly resolution is primarily driven by the light saturation of GPP. Temporal averaging reduces this non-linearity by reducing the impact of light saturated GPP at high PAR. Variations in $f_{\text {esc }}$ become more important to SIF at a half-hourly resolution and lead to a slight reduction in SIF at high light levels. Seasonally, SIF and GPP both vary with temperature and the light use efficiencies of fluorescence and photosynthesis $\left(\mathrm{LUE}_{\mathrm{F}}, \mathrm{GPP}_{\max }\right)$ generally co-vary across the seasonal cycle with sustained non-photochemical quenching. $f_{\text {esc }}$ does not play a significant role in the seasonal relationship between SIF and GPP. A small light response of SIF in winter, as well as small differences in the seasonal cycles of $\mathrm{LUE}_{\mathrm{F}}$ and $\mathrm{GPP}_{\max }$ lead to a seasonally variable SIF-GPP relationship. Accounting for this seasonally variable relationship will help improve the accuracy for SIF as a proxy for GPP.

Our results strongly support the value of SIF as a proxy for GPP in boreal forests, and emphasize the need for future research to further constrain the relationship under varying illumination and environmental conditions.

\section{Acknowledgments}

PhotoSpec SIF and VI data is available at https://doi.org/10.5281/zenodo.5884643. Environmental and eddy covariance data archiving is available at https://dx.doi.org/10.20383/102.0550. This work was supported by NASAs Earth Science Division IDS (awards 80NSSC17K0108 at UCLA, 80NSSC17K0110 at JPL) and ABoVE programs (award 80NSSC19M0130). A portion of this research was carried out at the Jet Propulsion Laboratory, California Institute of Technology, under a contract with the National Aeronautics and Space Administration.

This material is also based upon work supported by the National Science Foundation Graduate Research Fellowship under Grant No. DGE-1650604 and DGE-2034835. Any opinion, findings, and conclusions or recommendations expressed in this material 
are those of the authors(s) and do not necessarily reflect the views of the National Science Foundation.

DRB and TSM were funded during this time by the Macrosystems Biology and NEONEnabled Science program at NSF (award 1926090). AJM was supported by an appointment to the NASA Postdoctoral Program at the Jet Propulsion Laboratory, administered by Universities Space Research Association under contract with NASA.

We acknowledge funding by the Canadian Space Agency and Natural Sciences and Engineering Research Council of Canada (NSERC). The meteorological, soil and eddycovariance measurements at SOBS were made with support from the Global Institute for Water Security, University of Saskatchewan.

We thank our many collaborators, including site PIs and technicians, for their efforts in support of PhenoCam. The development of PhenoCam has been funded by the Northeastern States Research Cooperative, NSFs Macrosystems Biology program (awards EF-1065029 and EF-1702697), and DOEs Regional and Global Climate Modeling program (award DE-SC0016011). We acknowledge additional support from the US National Park Service Inventory and Monitoring Program and the USA National Phenology Network (grant number G10AP00129 from the United States Geological Survey), and from the USA National Phenology Network and North Central Climate Science Center (cooperative agreement number G16AC00224 from the United States Geological Survey).

\section{References}

Adams, W. W., \& DemmigAdams, B. (1994). Carotenoid composition and down regulation of photosystem II in three conifer species during the winter. Physiologia Plantarum, 92(3), 451-458. doi: 10.1111/j.1399-3054.1994.tb08835.x

Adams, W. W., Zarter, C. R., Ebbert, V., \& Demmig-Adams, B. (2004). Photoprotective Strategies of Overwintering Evergreens. BioScience, 54 (1), 41-49. doi: 10.1641/0006-3568(2004)054[0041:psooe]2.0.co;2

Anav, A., Friedlingstein, P., Beer, C., Ciais, P., Harper, A., Jones, C., ... Zhao, M. (2015). Reviews of Geophysics primary production : A review. Reviews of Geophysics, 1-34. doi: 10.1002/2015RG000483.Received

Badgley, G., Anderegg, L. D., Berry, J. A., \& Field, C. B. (2019). Terrestrial gross primary production: Using NIRV to scale from site to globe. Global Change Biology, 25(11), 3731-3740. doi: 10.1111/gcb.14729 
Badgley, G., Field, C. B., \& Berry, J. A. (2017). Canopy near-infrared reflectance and terrestrial photosynthesis. Science Advances, 3(3), e1602244. doi: 10 $.1126 /$ sciadv. 1602244

Bag, P., Chukhutsina, V., Zhang, Z., Paul, S., Ivanov, A. G., Shutova, T., ... Jansson, S. (2020). Direct energy transfer from photosystem II to photosystem I confers winter sustainability in Scots Pine. Nature Communications, 11(1), 1-13. doi: 10.1038/s41467-020-20137-9

Barr, A. G., Black, T. A., Hogg, E. H., Kljun, N., Morgenstern, K., \& Nesic, Z. (2004). Inter-annual variability in the leaf area index of a boreal aspenhazelnut forest in relation to net ecosystem production. Agricultural and Forest Meteorology, 126(3-4), 237-255. doi: 10.1016/j.agrformet.2004.06.011

Barr, A. G., Morgenstern, K., Black, T. A., McCaughey, J. H., \& Nesic, Z. (2006). Surface energy balance closure by the eddy-covariance method above three boreal forest stands and implications for the measurement of the CO2 flux. Agricultural and Forest Meteorology, 140(1-4), 322-337. doi: 10.1016/j.agrformet.2006.08.007

Bergeron, O., Margolis, H. A., Black, T. A., Coursolle, C., Dunn, A. L., Barr, A. G., \& Wofsy, S. C. $\quad(2007,1)$. Comparison of carbon dioxide fluxes over three boreal black spruce forests in canada. Global Change Biology, 13, 89-107. doi: 10.1111/j.1365-2486.2006.01281.x

Bonan, G. B. (2008). Forests and climate change: Forcings, feedbacks, and the climate benefits of forests. Science, 320(5882), 1444-1449. doi: 10.1126/science .1155121

Bowling, D. R., Logan, B. A., Hufkens, K., Aubrecht, D. M., Richardson, A. D., Burns, S. P., ... Eiriksson, D. P. (2018). Limitations to winter and spring photosynthesis of a Rocky Mountain subalpine forest. Agricultural and Forest Meteorology, 252, 241-255. doi: 10.1016/j.agrformet.2018.01.025

Breiman, L. (2001). Random forests. , 45, 5-32.

Chang, C. Y., Guanter, L., Frankenberg, C., Khler, P., Gu, L., Magney, T. S., ... Sun, Y. (2020, 7). Systematic assessment of retrieval methods for canopy far-red solar-induced chlorophyll fluorescence using high-frequency automated field spectroscopy. Journal of Geophysical Research: Biogeosciences, 125. doi: 10.1029/2019JG005533/FORMAT/PDF 
Chen, J. M., Govind, A., Sonnentag, O., Zhang, Y., Barr, A., \& Amiro, B. (2006). Leaf area index measurements at Fluxnet-Canada forest sites. Agricultural and Forest Meteorology, 140(1-4), 257-268. doi: 10.1016/j.agrformet.2006.08.005

Cheng, R., Magney, T. S., Dutta, D., Bowling, D. R., Logan, B. A., Burns, S. P., ... Frankenberg, C. (2020). Decomposing reflectance spectra to track gross primary production in a subalpine evergreen forest. Biogeosciences, 17(18), 4523-4544. doi: 10.5194/bg-17-4523-2020

Chu, H., Luo, X., Ouyang, Z., Chan, W. S., Dengel, S., Biraud, S. C., ... Zona, D. (2021, may). Representativeness of Eddy-Covariance flux footprints for areas surrounding AmeriFlux sites. Agricultural and Forest Meteorology, 301-302, 108350. doi: $10.1016 /$ j.agrformet.2021.108350

Commane, R., Lindaas, J., Benmergui, J., Luus, K. A., Chang, R. Y., Daube, B. C., ... Wofsy, S. C. (2017). Carbon dioxide sources from Alaska driven by increasing early winter respiration from Arctic tundra. Proceedings of the National Academy of Sciences of the United States of America, 114(21), 5361-5366. doi: $10.1073 /$ pnas. 1618567114

Damm, A., Guanter, L., Paul-Limoges, E., van der Tol, C., Hueni, A., Buchmann, N., ... Schaepman, M. E. (2015). Far-red sun-induced chlorophyll fluorescence shows ecosystem-specific relationships to gross primary production: An assessment based on observational and modeling approaches. Remote Sensing of Environment, 166, 91-105. doi: 10.1016/j.rse.2015.06.004

Dechant, B., Ryu, Y., Badgley, G., Zeng, Y., Berry, J. A., Zhang, Y., ... Moya, I. (2020). Canopy structure explains the relationship between photosynthesis and sun-induced chlorophyll fluorescence in crops. Remote Sensing of Environment, 241. doi: $10.1016 /$ j.rse.2020.111733

Demmig-Adams, B., \& Adams, W. W. (1992). Photoprotection and other responses of plants to high light stress. Annual Review of Plant Physiology and Plant Molecular Biology, 43(1), 599-626. doi: 10.1146/annurev.pp.43.060192 .003123

Ensminger, I., Sveshnikov, D., Campbell, D. A., Funk, C., Jansson, S., Lloyd, J., ... Öquist, G. (2004). Intermittent low temperatures constrain spring recovery of photosynthesis in boreal Scots pine forests. Global Change Biology, 10(6), 995-1008. doi: 10.1111/j.1365-2486.2004.00781.x 
Fisher, J. B., Hayes, D. J., Schwalm, C. R., Huntzinger, D. N., Stofferahn, E., Schaefer, K., ... Zhang, Z. (2018). Missing pieces to modeling the Arctic-Boreal puzzle. Environmental Research Letters, 13(2). ～doi: 10.1088/1748-9326/ aa9d9a

Frankenberg, C., \& Berry, J. (2017). Solar induced chlorophyll fluorescence: Origins, relation to photosynthesis and retrieval. Comprehensive Remote Sensing, 1-9(1986), 143-162. doi: 10.1016/B978-0-12-409548-9.10632-3

Frankenberg, C., Butz, A., \& Toon, G. C. ～(2011). Disentangling chlorophyll fluorescence from atmospheric scattering effects in O2 A-band spectra of reflected sun-light. Geophysical Research Letters, 38(3), n/a-n/a. doi: 10.1029/2010GL045896

Friedlingstein, P., Meinshausen, M., Arora, V. K., Jones, C. D., Anav, A., Liddicoat, S. K., \& Knutti, R. (2014). Uncertainties in CMIP5 climate projections due to carbon cycle feedbacks. Journal of Climate, 27(2), 511-526. doi: 10.1175/JCLI-D-12-00579.1

Fu, Z., Stoy, P. C., Luo, Y., Chen, J., Sun, J., Montagnani, L., ... Niu, S. (2017). Climate controls over the net carbon uptake period and amplitude of net ecosystem production in temperate and boreal ecosystems. Agricultural and Forest Meteorology, 243, 9-18. doi: 10.1016/j.agrformet.2017.05.009

Gamon, J. A., \& Berry, J. A. (2012). Facultative and constitutive pigment effects on the Photochemical Reflectance Index (PRI) in sun and shade conifer needles. Israel Journal of Plant Sciences, 60(1-2), 85-95. doi: 10.1560/IJPS.60.1-2.85

Gamon, J. A., Huemmrich, K. F., Wong, C. Y., Ensminger, I., Garrity, S., Hollinger, D. Y., .. Peñuelask, J. (2016). A remotely sensed pigment index reveals photosynthetic phenology in evergreen conifers. Proceedings of the National Academy of Sciences of the United States of America, 113(46), 13087-13092. doi: 10.1073/pnas.1606162113

Gamon, J. A., Peñuelas, J., \& Field, C. B. (1992). A narrow-waveband spectral index that tracks diurnal changes in photosynthetic efficiency. Remote Sensing of Environment, 41(1), 35-44. doi: 10.1016/0034-4257(92)90059-S

Gamon, J. A., Serrano, L., \& Surfus, J. S. (1997). The photochemical reflectance index: An optical indicator of photosynthetic radiation use efficiency across species, functional types, and nutrient levels. Oecologia, 112(4), 492-501. doi: 
Garbulsky, M. F., Peñuelas, J., Papale, D., Ardö, J., Goulden, M. L., Kiely, G., ... Filella, I. (2010). Patterns and controls of the variability of radiation use efficiency and primary productivity across terrestrial ecosystems. Global Ecology and Biogeography, 19(2), 253-267. doi: 10.1111/j.1466-8238.2009.00504.x

Goetz, S. J., Bunn, A. G., Fiske, G. J., \& Houghton, R. A. (2005). Satellite-observed photosynthetic trends across boreal North America associated with climate and fire disturbance (Vol. 102; Tech. Rep. No. 38). doi: 10.1073/pnas.0506179102

Government of Canada, Prince Albert Station. (2019). Canadian Climate Normals - Climate - Environment and Climate Change Canada, Prince Albert Station. Retrieved 2021-05-04, from https://climate.weather.gc.ca/ climate_normals/index_e.html

Grant, R., Margolis, H., Barr, A., Black, T., Dunn, A., Bernier, P., \& Bergeron, O. $(2009,1)$. Changes in net ecosystem productivity of boreal black spruce stands in response to changes in temperature at diurnal and seasonal time scales. Tree Physiology, 29, 1-17. doi: 10.1093/treephys/tpn004

Grossmann, K., Frankenberg, C., Magney, T. S., Hurlock, S. C., Seibt, U., \& Stutz, J. (2018). PhotoSpec: A new instrument to measure spatially distributed red and far-red Solar-Induced Chlorophyll Fluorescence. Remote Sensing of Environment, 216(November 2017), 311-327. doi: 10.1016/j.rse.2018.07.002

Gu, L., Han, J., Wood, J. D., Chang, C. Y., \& Sun, Y. ～(2019). S Sun-induced Chl fluorescence and its importance for biophysical modeling of photosynthesis based on light reactions. $\quad$ New Phytologist, 223(3), 1179-1191. doi: 10.1111/nph.15796

Guanter, L., Zhang, Y., Jung, M., Joiner, J., Voigt, M., Berry, J. A., ... Griffis, T. J. (2014). Global and time-resolved monitoring of crop photosynthesis with chlorophyll fluorescence. Proceedings of the National Academy of Sciences, 111(14), E1327-E1333. doi: 10.1073/PNAS.1320008111

He, L., Magney, T., Dutta, D., Yin, Y., Köhler, P., Grossmann, K., .. Frankenberg, C. (2020, apr). From the Ground to Space: Using Solar-Induced Chlorophyll Fluorescence to Estimate Crop Productivity. Geophysical Research Letters, 47(7), e2020GL087474. doi: 10.1029/2020GL087474

Jahns, P., \& Holzwarth, A. R. (2012). The role of the xanthophyll cycle and of 
lutein in photoprotection of photosystem II. Biochimica et Biophysica Acta Bioenergetics, 1817(1), 182-193. doi: 10.1016/j.bbabio.2011.04.012

Jarvis, P. G., Massheder, J. M., Hale, S. E., Moncrieff, J. B., Rayment, M., \& Scott, S. L. (1997). Seasonal variation of carbon dioxide, water vapor, and energy exchanges of a boreal black spruce forest. Journal of Geophysical Research Atmospheres, 102(24), 28953-28966. doi: 10.1029/97jd01176

Jeong, S. J., Schimel, D., Frankenberg, C., Drewry, D. T., Fisher, J. B., Verma, M., ... Joiner, J. (2017). Application of satellite solar-induced chlorophyll fluorescence to understanding large-scale variations in vegetation phenology and function over northern high latitude forests. Remote Sensing of Environment, 190, 178-187. doi: 10.1016/j.rse.2016.11.021

Kim, J., Ryu, Y., Dechant, B., Lee, H., Seok, H., Kornfeld, A., \& Berry, J. A. (2021). Remote Sensing of Environment Solar-induced chlorophyll fluorescence is non-linearly related to canopy photosynthesis in a temperate evergreen needleleaf forest during the fall transition. Remote Sensing of Environment, 258(August 2020), 112362. doi: 10.1016/j.rse.2021.112362

Köhler, P., Frankenberg, C., Magney, T. S., Guanter, L., Joiner, J., \& Landgraf, J. (2018). Global Retrievals of Solar-Induced Chlorophyll Fluorescence With TROPOMI: First Results and Intersensor Comparison to OCO-2. Geophysical Research Letters, 45(19), 10,456-10,463. doi: 10.1029/2018GL079031

Krause, G. H., \& Weis, E. (1991). Chlorophyll fluorescence and photosynthesis: The basics. Annual Review of Plant Physiology and Plant Molecular Biology, 42(1), 313-349. doi: 10.1146/annurev.pp.42.060191.001525

Liu, P., Black, T. A., Jassal, R. S., Zha, T., Nesic, Z., Barr, A. G., ... Ma, J. (2019). Divergent long-term trends and interannual variation in ecosystem resource use efficiencies of a southern boreal old black spruce forest 19992017. Global Change Biology, 25(9), 3056-3069. doi: 10.1111/gcb.14674

Luus, K. A., Commane, R., Parazoo, N. C., Benmergui, J., Euskirchen, E. S., Frankenberg, C., ... Lin, J. C. (2017). Tundra photosynthesis captured by satellite-observed solar-induced chlorophyll fluorescence. Geophysical Research Letters, 44 (3), 1564-1573. doi: 10.1002/2016GL070842

Magney, T. S., Barnes, M. L., \& Yang, X. (2020). On the Covariation of Chlorophyll Fluorescence and Photosynthesis Across Scales. Geophysical Research Letters, 
47(23). doi: 10.1029/2020gl091098

Magney, T. S., Bowling, D. R., Logan, B. A., Grossmann, K., Stutz, J., Blanken, P. D., ... Frankenberg, C. (2019). Mechanistic evidence for tracking the seasonality of photosynthesis with solar-induced fluorescence. Proceedings of the National Academy of Sciences of the United States of America, 116(24), 11640-11645. doi: 10.1073/pnas.1900278116

Magney, T. S., Frankenberg, C., Köhler, P., North, G., Davis, T. S., Dold, C., ... Porcar-Castell, A. (2019). Disentangling Changes in the Spectral Shape of Chlorophyll Fluorescence: Implications for Remote Sensing of Photosynthesis. Journal of Geophysical Research: Biogeosciences, 124(6), 1491-1507. doi: 10.1029/2019JG005029

Maguire, A. J., Eitel, J. U., Griffin, K. L., Magney, T. S., Long, R. A., Vierling, L. A., , . Bruner, S. G. (2020). On the Functional Relationship Between Fluorescence and Photochemical Yields in Complex Evergreen Needleleaf Canopies. Geophysical Research Letters, 47(9). doi: 10.1029/2020GL087858

Marrs, J. K., Reblin, J. S., Logan, B. A., Allen, D. W., Reinmann, A. B., Bombard, D. M., ... Hutyra, L. R. (2020). Solar-Induced Fluorescence Does Not Track Photosynthetic Carbon Assimilation Following Induced Stomatal Closure. Geophysical Research Letters, 47(15). doi: 10.1029/2020GL087956

MATLAB. (2021). version 9.11.0 (r2021b). Natick, Massachusetts: The MathWorks Inc.

Michaelis, L., \& Menten, M. L. (1913). Kinetik der Invertinwirkung. Biochem. z, $49(333369), 352$.

Middleton, E. M., Sullivan, J. H., Bovard, B. D., Deluca, A. J., Chan, S. S., \& Cannon, T. A. (1997). Seasonal variability in foliar characteristics and physiology for boreal forest species at the five Saskatchewan tower sites during the 1994 Boreal Ecosystem-Atmosphere Study. Journal of Geophysical Research Atmospheres, 102(24), 28831-28844. doi: 10.1029/97jd02560

Mohammed, G. H., Colombo, R., Middleton, E. M., Rascher, U., van der Tol, C., Nedbal, L., ... Zarco-Tejada, P. J. (2019, sep). Remote sensing of solarinduced chlorophyll fluorescence (SIF) in vegetation: 50 years of progress. Remote Sensing of Environment, 231, 111177. doi: 10.1016/J.RSE.2019.04.030

Monteith, J. L. (1972). Solar Radiation and Productivity in Tropical Ecosystems. 
The Journal of Applied Ecology, 9(3), 747. doi: 10.2307/2401901

Öquist, G., \& Huner, N. P. (2003). Photosynthesis of Overwintering Evergreen Plants. Annual Review of Plant Biology, 54, 329-355. doi: 10.1146/annurev .arplant.54.072402.115741

Pappas, C., Maillet, J., Rakowski, S., Baltzer, J. L., Barr, A. G., Black, T. A., ...

Zha, T. (2020). Aboveground tree growth is a minor and decoupled fraction of boreal forest carbon input. Agricultural and Forest Meteorology, 290(December 2019), 108030. doi: 10.1016/j.agrformet.2020.108030

Parazoo, N. C., Arneth, A., Pugh, T. A., Smith, B., Steiner, N., Luus, K., ...

Miller, C. (2018). Spring photosynthetic onset and net CO2 uptake in Alaska triggered by landscape thawing. Global Change Biology, 24(8), 3416-3435. doi: $10.1111 / \mathrm{gcb} .14283$

Parazoo, N. C., Frankenberg, C., Köhler, P., Joiner, J., Yoshida, Y., Magney, T., ... Yadav, V. (2019). Towards a Harmonized Long-Term Spaceborne Record of Far-Red Solar-Induced Fluorescence. Journal of Geophysical Research: Biogeosciences, 124(8), 2518-2539. doi: 10.1029/2019JG005289

Pierrat, Z., Nehemy, M. F., Roy, A., Magney, T., Parazoo, C., Laroque, C., ...

Stutz, J. (2021). Tower-based remote sensing reveals mechanisms behind a two-phased spring transition in a mixed-species boreal forest. Journal of Geophysical Research: Biogeosciences.

Porcar-Castell, A. (2011). A high-resolution portrait of the annual dynamics of photochemical and non-photochemical quenching in needles of $\mathrm{Pi}$ nus sylvestris. Physiologia Plantarum, 143(2), 139-153. doi: 10.1111/ j.1399-3054.2011.01488.x

Porcar-Castell, A., Juurola, E., Nikinmaa, E., Berninger, F., Ensminger, I., \& Hari, P. (2008). Seasonal acclimation of photosystem II in Pinus sylvestris. I. Estimating the rate constants of sustained thermal energy dissipation and photochemistry. Tree Physiology, 28(10), 1475-1482. doi: $10.1093 /$ treephys/28.10.1475

Porcar-Castell, A., Malenovský, Z., Magney, T., Van Wittenberghe, S., FernándezMarín, B., Maignan, F., .. Logan, B. (2021). Chlorophyll a fluorescence illuminates a path connecting plant molecular biology to Earth-system science. Nature Plants, 7(8), 998-1009. doi: 10.1038/s41477-021-00980-4 
Porcar-Castell, A., Tyystjärvi, E., Atherton, J., Van Der Tol, C., Flexas, J., Pfündel, E. E., ... Berry, J. A. (2014). Linking chlorophyll a fluorescence to photosynthesis for remote sensing applications: Mechanisms and challenges. Journal of Experimental Botany, 65(15), 4065-4095. doi: 10.1093/jxb/eru191

Raczka, B., Porcar-Castell, A., Magney, T., Lee, J. E., Köhler, P., Frankenberg, C., .. Bowling, D. R. (2019). Sustained Nonphotochemical Quenching Shapes the Seasonal Pattern of Solar-Induced Fluorescence at a High-Elevation Evergreen Forest. Journal of Geophysical Research: Biogeosciences, 124(7), 2005-2020. doi: 10.1029/2018JG004883

Schaefer, K., Lantuit, H., Romanovsky, V. E., Schuur, E. A., \& Witt, R. (2014). The impact of the permafrost carbon feedback on global climate. Environmental Research Letters, 9(8). doi: 10.1088/1748-9326/9/8/085003

Sims, D. A., Luo, H., Hastings, S., Oechel, W. C., Rahman, A. F., \& Gamon, J. A. (2006). Parallel adjustments in vegetation greenness and ecosystem $\mathrm{CO} 2$ exchange in response to drought in a Southern California chaparral ecosystem. Remote Sensing of Environment, 103(3), 289-303. doi: 10.1016/j.rse.2005.01.020

Sims, D. A., Rahman, A. F., Cordova, V. D., El-Masri, B. Z., Baldocchi, D. D., Flanagan, L. B., .. Xu, L. (2006). On the use of MODIS EVI to assess gross primary productivity of North American ecosystems. Journal of Geophysical Research: Biogeosciences, 111(4). doi: 10.1029/2006JG000162

Springer, K. R., Wang, R., \& Gamon, J. A. (2017). Parallel seasonal patterns of photosynthesis, fluorescence, and reflectance indices in boreal trees. Remote Sensing, 9(7). doi: 10.3390/rs9070691

Stylinski, C. D., Gamon, J. A., \& Oechel, W. C. $\quad$ (2002). Seasonal patterns of reflectance indices, carotenoid pigments and photosynthesis of evergreen chaparral species. Oecologia, 131 (3), 366-374. doi: 10.1007/s00442-002-0905-9

Sun, Y., Frankenberg, C., Jung, M., Joiner, J., Guanter, L., Köhler, P., \& Magney, T. (2018). Overview of Solar-Induced chlorophyll Fluorescence (SIF) from the Orbiting Carbon Observatory-2: Retrieval, cross-mission comparison, and global monitoring for GPP. Remote Sensing of Environment, 209(February), 808-823. doi: 10.1016/j.rse.2018.02.016

Sun, Y., Frankenberg, C., Wood, J. D., Schimel, D. S., Jung, M., Guanter, L., 
... Yuen, K. (2017). OCO-2 advances photosynthesis observation from space via solar-induced chlorophyll fluorescence. Science, 358(6360). doi: 10.1126/science.aam5747

Thurner, M., Beer, C., Santoro, M., Carvalhais, N., Wutzler, T., Schepaschenko, D.,... Schmullius, C. (2014). Carbon stock and density of northern boreal and temperate forests. Global Ecology and Biogeography, 23(3), 297-310. doi: $10.1111 /$ geb. 12125

Tucker, C. J. (1979). Red and photographic infrared linear combinations for monitoring vegetation. Remote Sensing of Environment, 8(2), 127-150. doi: 10 .1016/0034-4257(79)90013-0

Van Der Tol, C., Berry, J. A., Campbell, P. K., \& Rascher, U. (2014, dec). Models of fluorescence and photosynthesis for interpreting measurements of solarinduced chlorophyll fluorescence. Journal of Geophysical Research: Biogeosciences, 119(12), 2312-2327. doi: 10.1002/2014JG002713

Verhoeven, A. (2014). Sustained energy dissipation in winter evergreens (Vol. 201) (No. 1). doi: 10.1111/nph.12466

Walther, S., Voigt, M., Thum, T., Gonsamo, A., Zhang, Y., Köhler, P., ... Guanter, L. (2016). Satellite chlorophyll fluorescence measurements reveal large-scale decoupling of photosynthesis and greenness dynamics in boreal evergreen forests. Global change biology, 22(9), 2979-2996. doi: 10.1111/gcb.13200

Wang, B., Tian, Z., Zhang, W., Chen, G., Guo, Y., \& Wang, M. (2019). Retrieval of Green-up Onset Date from MODIS Derived NDVI in Grasslands of Inner Mongolia. IEEE Access, 7, 77885-77893. doi: 10.1109/ACCESS.2019.2922003

Wong, C. Y., \& Gamon, J. A. (2015a). The photochemical reflectance index provides an optical indicator of spring photosynthetic activation in evergreen conifers. New Phytologist, 206(1), 196-208. doi: 10.1111/nph.13251

Wong, C. Y., \& Gamon, J. A. (2015b). Three causes of variation in the photochemical reflectance index (PRI) in evergreen conifers. New Phytologist, 206(1), 187-195. doi: 10.1111/nph.13159

Yang, H., Yang, X., Heskel, M., Sun, S., \& Tang, J. (2017). Seasonal variations of leaf and canopy properties tracked by ground-based NDVI imagery in a temperate forest. Scientific Reports, 7(1). doi: 10.1038/s41598-017-01260-y

Yang, X., Tang, J., Mustard, J. F., Lee, J. E., Rossini, M., Joiner, J., .. Richard- 
son, A. D. (2015). Solar-induced chlorophyll fluorescence that correlates with canopy photosynthesis on diurnal and seasonal scales in a temperate deciduous forest. Geophysical Research Letters, 42(8), 2977-2987. doi: 10.1002/2015GL063201

Zeng, Y., Badgley, G., Dechant, B., Ryu, Y., Chen, M., \& Berry, J. A. A practical approach for estimating the escape ratio of near-infrared solarinduced chlorophyll fluorescence. Remote Sensing of Environment, 232(July), 111209. doi: 10.1016/j.rse.2019.05.028 